This document is the accepted version of a published work that appeared in final form in Nature Genetics, after technical editing by the publisher. To access the final edited and published work, see https://doi.org/10.1038/ng.3282

\title{
Mutations in KCNH1 and ATP6V1B2 cause Zimmermann-Laband syndrome
}

Fanny Kortüm ${ }^{1,21}$, Viviana Caputo ${ }^{2,21}$, Christiane K. Bauer ${ }^{3,21}$, Lorenzo Stella ${ }^{4}$, Andrea Ciolfi $^{2,5}$, Malik Alawi ${ }^{6,7,8}$, Gianfranco Bocchinfuso ${ }^{4}$, Elisabetta Flex ${ }^{5}$, Stefano Paolacci ${ }^{2,5}$, Maria Lisa Dentici ${ }^{9}$, Paola Grammatico ${ }^{10}$, Georg Christoph Korenke ${ }^{11}$, Vincenzo Leuzzi $^{12}$, David Mowat ${ }^{13,14}$, Lal D. V. Nair ${ }^{15}$, Thi Tuyet Mai Nguyen ${ }^{16}$, Patrick Thierry ${ }^{17}$, Susan M. White ${ }^{18,19}$, Bruno Dallapiccola ${ }^{9}$, Antonio Pizzuti ${ }^{2}$, Philippe M. Campeau ${ }^{20}$, Marco Tartaglia ${ }^{4,9,22}$, Kerstin Kutsche $e^{1,22}$

${ }^{1}$ Institute of Human Genetics, University Medical Center Hamburg-Eppendorf, Hamburg, Germany.

${ }^{2}$ Dipartimento di Medicina Sperimentale, Università La Sapienza, Rome, Italy. ${ }^{3}$ Department of Cellular and Integrative Physiology, University Medical Center HamburgEppendorf, Hamburg, Germany.

${ }^{4}$ Dipartimento di Scienze e Tecnologie Chimiche, Università “Tor Vergata”, Rome, Italy. ${ }^{5}$ Dipartimento di Ematologia, Oncologia e Medicina Molecolare, Istituto Superiore di Sanità, Rome, Italy.

${ }^{6}$ University Medical Center Hamburg-Eppendorf, Bioinformatics Service Facility, Hamburg, Germany.

${ }^{7}$ Center for Bioinformatics, University of Hamburg, Hamburg, Germany.

${ }^{8}$ Heinrich-Pette-Institute, Leibniz-Institute for Experimental Virology, Virus Genomics, Hamburg, Germany.

${ }^{9}$ Ospedale Pediatrico Bambino Gesù- IRCSS, Rome, Italy.

${ }^{10}$ Dipartimento di Medicina Molecolare, Università La Sapienza, Ospedale San CamilloForlanini, Rome, Italy.

${ }^{11}$ Zentrum für Kinder- und Jugendmedizin, Neuropädiatrie, Klinikum Oldenburg gGmbH, Oldenburg, Germany.

${ }^{12}$ Dipartimento di Pediatria e Neuropsichiatria Infantile, Università La Sapienza, Rome, Italy.

${ }^{13}$ Department of Medical Genetics, Sydney Children’s Hospital, Sydney, Australia. 
${ }^{14}$ School of Women's and Children's Health, UNSW Medicine, University of New South Wales, Sydney, Australia.

${ }^{15}$ Department of Pediatrics, Saveetha Medical College and Hospital, Saveetha University, Chennai, Tamil Nadu, 600077, India.

${ }^{16}$ Sainte-Justine Hospital Research Center, University of Montreal, Montreal, QC, Canada.

${ }^{17}$ Service de Pédiatrie, CHI Haute-Saône, Vesoul, France.

${ }^{18}$ Victorian Clinical Genetics Services, Murdoch Childrens Research Institute, Royal

Children’s Hospital, Melbourne, Australia.

${ }^{19}$ Department of Paediatrics, University of Melbourne, Australia.

${ }^{20}$ Department of Pediatrics, Sainte-Justine Hospital, University of Montreal, Montreal, QC, Canada.

${ }^{21}$ These authors contributed equally to this project.

${ }^{22}$ These authors jointly directed this project.

\section{Corresponding authors:}

Kerstin Kutsche, PhD

Institute of Human Genetics

University Medical Center Hamburg-Eppendorf

Martinistraße 52

20246 Hamburg, Germany

phone: +49 40 741054597, fax: +49 40 741055138, email: kkutsche@uke.de

Marco Tartaglia, PhD

Dipartimento di Ematologia, Oncologia e Medicina Molecolare

Istituto Superiore di Sanità

Viale Regina Elena, 299

00161 Rome, Italy

phone: +39 06 49902569, fax: + 3906 49387143, email: marco.tartaglia@iss.it 
Zimmermann-Laband syndrome (ZLS) is a developmental disorder characterized by facial dysmorphism with early onset gingival enlargement, intellectual disability, hypo/aplasia of nails and terminal phalanges of hands and feet, and hypertrichosis ${ }^{1-4}$. We report that heterozygous missense mutations in $K C N H 1$ account for a significant proportion of ZLS. KCNH1 encodes Eag1/Kv10.1, a member of the ether-à-go-go family of voltage-gated $\mathrm{K}^{+}$channels. Patch-clamp recordings in cells expressing homomeric KCNH1 mutant channels revealed a shift in the threshold for $\mathrm{K}^{+}$current activation to more negative potentials for all but one mutant (G469R). For the latter, co-expression experiments demonstrated a dominant action over the wild-type channel, with reduced $\mathrm{K}^{+}$conductance of the heterotetrameric channels at depolarizing potentials but a pronounced conductance at negative potentials. These data support a gain-of-function effect of all KCNH1 mutants. We also report that a single missense change in ATP6V1B2 underlie a small fraction of ZLS. ATP6V1B2 encodes the B2 subunit of the vacuolar $\mathrm{H}^{+}$ATPase, a multimeric enzyme that mediates acidification in organelles by pumping protons against an electrochemical gradient. Structural analysis indicated a possible perturbing effect of the introduced residue on complex assembly. Our findings provide evidence that disturbances in voltage-dependent $\mathrm{K}^{+}$currents cause the clinically recognizable ZLS phenotype, and document genetic heterogeneity for this disorder.

The main clinical characteristics of ZLS (MIM 135500) are gingival fibromatosis, bulbous soft nose, thick floppy ears, nail aplasia or hypoplasia, hypertrichosis, joint hyperextensibility, hepato(spleno)megaly, and intellectual disability with or without epilepsy. Most cases are sporadic, suggesting autosomal dominant inheritance with de novo mutations ${ }^{5}$. Two translocations sharing a common 3p14.3 breakpoint region, including the genes CACNA2D3 and WNT5A, have been associated with ZLS ${ }^{6-8}$. In one individual, the CACNA2D3 gene, which encodes the auxiliary $\alpha 2 \delta-3$ subunit of voltage-gated $\mathrm{Ca}^{2+}$ channels, was found to be disrupted ${ }^{7}$. As the control of $\mathrm{Ca}^{2+}$ influx mediates many physiological 
processes, such as neuronal excitability and muscle contraction ${ }^{9,10}$ and calcium channel blockers can induce gingival overgrowth ${ }^{11}$, CACNA2D3 dysfunction has been suggested to underlie ZLS ${ }^{7}$. However, neither additional mutations in CACNA2D3 and/or WNT5A have yet been identified ${ }^{6,12}$ nor any other causative gene for this disease.

We performed whole-exome sequencing (WES) on five unrelated subjects with the most convincing clinical ZLS phenotype (subjects 1, 4, 5, 7 and 8) and the healthy parents of four of them (Online Methods). Subjects 5, 7 and 8 have been reported previously as individuals with typical ZLS (subject 7 in ref. 7,12 and subjects 5 and 8 in ref. 5). Following variant calling and annotation, WES data were processed to identify the genes that were shared among unrelated patients (at least two subjects) having functionally relevant variants (novel, clinically associated or with low/unknown frequency), taking into account X-linked, autosomal recessive and autosomal dominant inheritance models (Supplementary Table 1). These analyses identified one to seven putatively de novo variants in the four parent-child trios (Supplementary Table 2). Although no gene was shared by all samples, KCNH1 had putative de novo variants shared by subjects 1 (c.1399A>G, p.I467V), 4 (c.1405G>A, p.G469R), and 5 (c.1054C>G, p.L352V) (Fig. 1a and Supplementary Table 1). Subjects 7 and 8 shared an identical de novo missense variant in ATP6V1B2 (c.1454G>C, p.R485P) (Fig. 1a and Supplementary Table 1). The KCNH1 and ATP6V1B2 nonsynonymous variants were validated by Sanger sequencing, and parental genotyping confirmed their de novo origin. DNA from multiple tissues was available for subjects 4 and 5 (mutated KCNH1 allele), and subject 7 (ATP6V1B2 mutation). Sequencing confirmed occurrence of the variants in all examined tissues (Supplementary Fig. 1), indicating an early postzygotic mutational event or germline origin. We next screened 19 additional individuals exhibiting clinical features fitting ZLS or suggestive of the disorder for mutations in the KCNH1 and ATP6V1B2 coding regions and adjacent intronic stretches by Sanger sequencing. Two KCNH1 missense changes, the already identified c.1399A>G (p.I467V) substitution and c.1042G>A (p.G348R), were found 
to occur as de novo mutations in subjects 6 and 3, respectively (Fig. 1a). Two heterozygous variants (c.974C>A, p.S325Y; c.1066G>C, p.V356L) were documented in one additional individual (subject 2) (Fig. 1a); both variants were de novo, and demonstrated to be in cis (Supplementary Fig. 1). None of the identified de novo changes was annotated in dbSNP138, 1,000 Genomes, Exome Variant Server and ExAC databases. Both KCNH1 and ATP6V1B2 are predicted to be intolerant to functional genetic variation. ${ }^{13,14}$ Consistently, all mutations affected residues conserved through evolution, and invariantly observed among vertebrates (Supplementary Fig. 2), and were predicted to have damaging impact on protein function (Supplementary Table 3). Overall, identification of a KCNH1 or ATP6V1B2 mutation in eight out of 24 analyzed patients indicates further genetic heterogeneity in ZLS. KCNH1 is one of eight genes encoding the EAG (ether-à-go-go) family of voltage-gated $\mathrm{K}^{+}$channels comprising two members of the Eag (Kv10), three of Erg (Kv11), and three of Elk (Kv12) subfamilies ${ }^{15}$. The Eag1 channel encoded by KCNH1 conducts a typical delayedrectifier $\mathrm{K}^{+}$current, activates at relatively depolarized potentials, and marginally inactivates at more positive potentials ${ }^{16}$. KCNH1 subunits exhibit a typical Kv membrane topology with six transmembrane domains (S1-S6) and a pore-lining loop (located between S5 and S6) (Fig. 1b). The S1-S4 segments act as voltage sensor domains and the assembly of four subunits is required to form a functional channel. Affected amino acid residues were located in different domains of the channel. Ser325 and Gly348 are placed in the voltage-sensing S4 helix and S4-S5 linker, respectively, while the remaining residues localize within the S5 (Leu352 and Val356) and S6 (Ile467 and Gly469) transmembrane segments (Fig. 1b). The structural impact of four of the six mutations was explored by using a homology model for the helices S5 and S6 in the closed and open state of the channel. In the closed state, the Gly469 residues of two KCNH1 monomers are located close to each other, while they are farther apart in the open structure (Fig. 3a,b). Based on these structural observations, the p.G469R change, which inserts four cationic residues very close to each other in the closed state of the homotetramer, 
was predicted to impair tetramer formation or favor the open state. In the latter case, however, a lower conductance is to be expected, due to the presence of cationic residues close to the mouth of the channel. A similar effect would be expected also in heterotetramers composed of wild-type and mutant KCNH1 subunits. Residues Ile467, Leu352 and Val356 form a tight hydrophobic cluster in the open structure, which rearranges in the closed conformation (Fig. 3a). Perturbations of these residues were predicted to affect the closed-open conformational transition. Consistently, mutations in $K C N H 2$ affecting residues corresponding to Ile467 and Gly469 in KCNH1 have been demonstrated to favor the open state of the encoded ERG1 channel ${ }^{17,18}$.

We assessed the functional consequences of the KCNH1 mutations identified in ZLSaffected individuals by carrying out patch-clamp recordings from CHO cells expressing wildtype or mutant KCNH1 channels. Outward-rectifying essentially non-inactivating currents were elicited upon depolarizing test pulses for wild-type KCNH1 and the G348R, L352V, I467V and S325Y/V356L KCNH1 mutants, consistent with the expression of functional channels (Fig. 4a). Current amplitudes of the mutants did not differ significantly from wildtype KCNH1 amplitudes, but all mutant channels exhibited a remarkable shift in the threshold for $\mathrm{K}^{+}$current activation to more negative potentials (Fig. 4b), producing dramatic increases in whole cell $\mathrm{K}^{+}$conductance in the negative potential range (Fig. 4c). This effect resulted from strong shifts in the voltage dependence of KCNH1 channel activation to more negative potentials (Fig. 4d and Supplementary Table 4). These calculated differences in the voltage for half maximal channel activation were confirmed in experiments enabling instantaneous tail current measurements (Supplementary Fig. 3). We observed significantly accelerated channel activation and slower deactivation kinetics of the mutant channels compared to wildtype (Supplementary Fig. 4). Additional experiments showed that the altered voltage dependence of the double S325Y/V356L mutant resulted from additive effects produced by both amino acid substitutions (Supplementary Fig. 5 and Supplementary Table 4). Co- 
expression of wild-type KCNH1 and the G348R mutant, which exhibited the smallest shift in voltage dependence (Fig. $\mathbf{4 d )}$, resulted in currents with an intermediate activation threshold and voltage values for half maximal conductance still $20 \mathrm{mV}$ more negative than measured for wild-type channels (Fig. 5a-c and Supplementary Table 4). These data indicate that the four KCNH1 mutations G348R, L352V, I467V and S325Y/V356L have a gain-of-function effect. In contrast, voltage-dependent outward currents were not recorded in CHO cells expressing homomeric G469R KCNH1 channels (Fig. 4a and b inset), which was consistent with the gathered structural data. We next co-expressed wild-type and G469R KCNH1 alleles in CHO cells. While the resulting current profile overlapped that observed for the wild-type homotetramer, an additional smaller component with half-maximal conductance at about -45 $\mathrm{mV}$, and a small leakage $\mathrm{K}^{+}$current evident at negative potentials was recorded (Fig. $\mathbf{5 d - f}$ and Supplementary Table 4). The mean outward current amplitude at $+40 \mathrm{mV}$ corresponded to $69.9 \%$ of the respective wild-type channel value (SEM: 10.9\%; $\mathrm{p}=0.12$ ) (Fig. 5e, inset). Since KCNH1 expression levels varied considerably in CHO cells, we used Xenopus oocytes and found that co-expression of G469R and wild-type KCNH1 resulted in significantly smaller current amplitudes at $+40 \mathrm{mV}$ compared to homomeric wild-type channels (Supplementary Fig. 6). Similar to CHO cells, no depolarization-activated currents were recorded, when homomeric G469R mutant channels were expressed. These data document a dominant action of the G469R mutant over the wild-type channel, with reduced $\mathrm{K}^{+}$ conductance of the heterotetrameric channels at depolarizing potentials but a pronounced conductance at negative potentials similar to the other four ZLS-causing KCNH1 mutants. Together, these data provide evidence for a gain-of-function effect of all disease-associated KCNH1 mutant channels, similarly to the recently identified $K C N H 5$ mutation p.R327H in a patient with severe epileptic encephalopathy ${ }^{19}$, demonstrated to cause a strong hyperpolarizing shift in voltage dependence of activation favoring the open state of the EAG2 channel $^{20}$. 
The ATP6V1B2 gene was found to be mutated in two ZLS-affected individuals. It encodes one of two B subunits (B1 and B2) of the vacuolar $\mathrm{H}^{+}$-ATPase (V-ATPase), a multisubunit enzyme that mediates acidification in organelles by pumping protons against an electrochemical gradient ${ }^{21}$. V-ATPases comprise a cytoplasmic catalytic $\mathrm{V}_{1}$ subcomplex (subunits $\mathrm{A}_{3} \mathrm{~B}_{3} \mathrm{CDE}_{3} \mathrm{FG}_{3} \mathrm{H}$ ) and a membrane-embedded $\mathrm{V}_{0}$ subcomplex (subunits a, c, c', $c^{\prime \prime}$, d, and e) (Fig. 1c). Alternating A and B subunits form a heterohexameric ring structure that is linked to the $\mathrm{V}_{0}$ subcomplex by the $\mathrm{C}-\mathrm{H}$ subunits. ATP hydrolysis in the $\mathrm{A}_{3} \mathrm{~B}_{3}$ motor is required for proton translocation in $\mathrm{V}_{0}{ }^{22}$. No crystallographic structure of a B subunit of eukaryotic V-ATPase is available. To explore the structural impact of the R485P amino acid change, a homology model of the B2 subunit was generated and inserted into the crystallographic structure of the $\mathrm{A}_{3} \mathrm{~B}_{3}$ hexamer of $E$. hirae ATPase bound to a nonhydrolyzable ATP analog (PDB code 3vr3) ${ }^{23}$. Arg485 is far from the ATP binding site, and therefore is not expected to have any direct effect on the protein affinity for its substrate (Fig. 3e). The residue, however, is placed in an alpha-helical segment that is predicted to be disrupted by substitution to proline. Moreover, it forms a salt bridge with Asp507, which is lost in the mutant protein (Fig. 3f). Based on these considerations, the Arg-to-Pro substitution is predicted to destabilize the C-terminal segment of the B subunit, which is part of the A/B interface and has been demonstrated to interact with the $\mathrm{E}$ subunit ${ }^{24}$. This effect is expected to perturb intersubunit interactions in the $\mathrm{V}_{1}$ subcomplex.

In this work, we provided genetic, structural and functional evidence supporting the dysregulation of KCNH1 in ZLS pathogenesis. KCNH1 is predominantly expressed in the brain $^{25}$. The protein was detected in restricted peripheral cell populations, and ectopic expression of the channel has been found in diverse tumors ${ }^{26,27}$. Although the physiological role of the KCNH1 channel remains unclear, an involvement in cell cycle control and cell proliferation has been documented ${ }^{28,29}$. Interestingly, KCNH1 has recently been found to regulate cell proliferation, and enhance osteogenesis in human bone marrow-derived 
mesenchymal stem cells ${ }^{30}$, suggesting a more general role of KCNH1 in development. Kcnh1 null mice, however, develop normally, and brain morphology also appears normal. Beside mild hyperactivity, the mice display otherwise normal behavior ${ }^{31}$. These data suggest that KCNH1 null alleles are likely to be tolerated during development, while mutations leading to hyperactive KCNH1 channels significantly perturb developmental and physiological processes. KCNH1 channels contribute to resting membrane potentials in the range of -40 $\mathrm{mV}^{15}$, thus close to the activation threshold of L-type voltage-gated calcium channels ${ }^{32}$. All ZLS-causing KCNH1 amino acid substitutions induce a considerable $\mathrm{K}^{+}$conductance at negative potentials. Stabilization of the resting membrane potential of mutant KCNH1 channel-expressing cells in a more negative voltage range would impede opening of both voltage-gated $\mathrm{Na}^{+}$and $\mathrm{Ca}^{2+}$ channels. Thus, functional blockage of these channels could be a secondary effect of the $K C N H 1$ mutations, which may explain the similarity of the gingival enlargement in ZLS-affected subjects to what is observed in some individuals treated with the $\mathrm{Na}^{+}$channel blocker phenytoin ${ }^{33,34}$ or the $\mathrm{Ca}^{2+}$ channel blocker nifedipine ${ }^{35}$.

Developmental defects have rarely been associated with potassium channelopathies. However, Cantú syndrome, a disorder of congenital hypertrichosis, coarse facial features, osteochondrodysplasia and cardiomegaly, is caused by dominant missense mutations in KCNJ8 and ABCC9, encoding the ATP-sensitive potassium ( $\left.\mathrm{K}_{\mathrm{ATP}}\right)$ channel Kir 6.1 and one of its regulatory subunit (referred to as SUR2), respectively ${ }^{36-39}$. The mutations in both KCNJ8 and $A B C C 9$ reduce the ATP-dependent inhibition of the $\mathrm{K}_{\mathrm{ATP}}$ channel and result in enhanced channel activity ${ }^{36,39}$. These data together with our findings clearly demonstrate that a balance of potassium channel activities is not only critical for neurons but also for other cell types and tissues during embryonic development.

Our genetic data also provide evidence that alterations of the B2 subunit of the VATPase also account for a small proportion of ZLS. ATP6V1B2 is ubiquitously expressed, with high expression in brain and kidney, and it is the only subunit B isoform expressed in 
osteoclasts, suggesting an involvement in regulating proton secretion and bone reabsorption ${ }^{40-}$ ${ }^{42}$. Recently, a heterozygous nonsense mutation, c.1516C >T (p.R506*), in ATP6V1B2 has been reported in dominant deafness-onychodystrophy syndrome (DDOD; MIM 124480) ${ }^{43}$. Consistent with the partial clinical overlap between ZLS and DDOD, the ZLS- and DDODcausing ATP6V1B2 mutations affect the same region of the protein, which is involved in the formation of $\mathrm{V}_{1}$ subcomplex assembly. Truncation of the same C-terminal segment of ATP6V1B1 has been reported to disrupt $\mathrm{V}_{1}$ assembly and impair ATPase function ${ }^{24}$. While a defective function of the vacuolar ATPase has been reported for the p.R506* mutation $^{43}$, and a qualitatively similar disruptive effect for the R485P mutation cannot be ruled out, further studies are required to understand the precise consequences of both disease-causing mutations on V-ATPase function.

ZLS belongs to a group of syndromes which are characterized by considerable clinical overlap and genetic heterogeneity, such as Temple-Baraitser syndrome (TBS; MIM $611816)^{44}$, DDOD $^{45}$, and autosomal recessive DOORS (deafness, onychodystrophy, osteodystrophy, mental retardation, seizures) syndrome (MIM 220500) ${ }^{46}$. Intellectual disability, epilepsy, deafness, hypoplasia/aplasia of nails and/or terminal phalanges, gingival enlargement and hirsutism can be seen in the affected individuals, but vary between the different disorders as well as within each condition. The common clinical features in KCNH1and ATP6V1B2-mutation positive individuals reported here include craniofacial dysmorphism, gingival enlargement (preceding any anticonvulsant use in all subjects to our knowledge), mild to severe intellectual disability, aplastic/hypoplastic nails and terminal phalanges, and hypertrichosis (Fig. 2, Table 1 and Supplementary Table 5).

Seizures/epilepsy were present in all six KCNH1-mutation positive subjects but absent in the two individuals with ATP6V1B2 mutation, who exhibited more coarse facial features (Fig. 2, Table 1 and Supplementary Table 5). Of note, other clinical features, such as hearing loss, gingival enlargement, nail and skeletal defects, and hypertrichosis were variably present in the 
eight individuals with a KCNH1 or ATP6V1B2 mutation (Table 1 and Supplementary Table 5). Recently, de novo KCNH1 gain-of-function mutations have been reported in individuals with $\mathrm{TBS}^{47}$, further indicating that both TBS and ZLS belong to a phenotypic continuum that needs to be characterized in detail in the future.

In conclusion, by discovering de novo missense mutations in KCNH1 and ATP6V1B2 in individuals with ZLS we identified two disease genes for this multi-systemic disorder, and provided evidence for its genetic heterogeneity. Although the underlying pathomechanism involving altered KCNH1 channel and V-ATPase function has to be elucidated in the future, potential physiological links between the two proteins already exist. Both the V-ATPase and KCNH1 have been shown to regulate neurotransmitter release and are important for synaptic transmission ${ }^{48,49}$. The proton-pumping V-ATPase is required for generation and maintenance of the interior $\mathrm{pH}$ of intracellular organelles ${ }^{50}$. Proton pumping across the membrane generates a transmembrane voltage that has to be accompanied by the movement of a counterion to dissipate this voltage difference. Several experiments indicate that the net positive charge can be dissipated by $\mathrm{K}^{+}$efflux $^{51,52}$, and that both the V-ATPase and the counterion transporter are important elements in determining and regulating the steady-state $\mathrm{pH}$ of lysosomes and other cellular organelles ${ }^{50,51}$. Although no cation channel has yet emerged as candidate transporter, rapid internalization of plasma membrane-localized KCNH1 and its sorting to lysosomes ${ }^{53}$ provide a first clue that this potassium channel may function in lysosomal conductive pathways. An alternative scenario would be that altered acidification of various intracellular compartments may lead to disturbances in cellular transport processes in general, and perturbed regulation of KCNH1 trafficking in particular ${ }^{53,54}$.

\section{URLs}


1000 Genomes Project, http://www.1000genomes.org/; database for nonsynonymous SNPs' functional predictions (dbNSFP), https://sites.google.com/site/jpopgen/dbNSFP; dbSNP, http://www.ncbi.nlm.nih.gov/projects/SNP/snp_summary.cgi; dbSNP, http://www.ncbi.nlm.nih.gov/SNP/; ExAC database, http://exac.broadinstitute.org/; Exome Variant Server, National Heart, Lung, and Blood Institute (NHLBI) Grand Opportunity (GO) Exome Sequencing Project (ESP), http://evs.gs.washington.edu/EVS/; Gene, http://www.ncbi.nlm.nih.gov/gene/; Online Mendelian Inheritance in Man (OMIM), http://www.omim.org/; PDB, http://www.rcsb.org/pdb/home/home.do.

\section{ACKNOWLEDGEMENTS}

We are grateful to the patients and their families who contributed to this study. We thank Inka Jantke, Serena Cecchetti and Serenella Venanzi for skilful technical assistance, Telse Kock for site-directed mutagenesis, Annett Hasse for $\mathrm{CHO}$ cell transfection and injection, Robert Bähring, Joana M. Schröder and Eike Neumann for help with the oocyte experiments, Peter Meinecke for discussing clinical phenotypes, and Anna Podolska for help with ATP6V1B2 sequencing. G.B., L.S. and M.T. acknowledge CINECA for computational resources (WES data and structural analyses). The KCNH1/heag1 clone was kindly provided by S.H. Heinemann. This work was supported by grants from the Deutsche Forschungsgemeinschaft (KO 4576/1-1 to F.K. and KU 1240/5-1 to K.K.), Istituto Superiore di Sanità (Ricerca Corrente 2013 to M.T.), Ministero della Salute (Ricerca Finalizzata RF-2010-2312766 to B.D.) and Ospedale Pediatrico Bambino Gesù (Gene-Rare to B.D.).

\section{AUTHOR CONTRIBUTIONS}

F.K. performed WES data analysis and validation, molecular screening, genotyping and wrote the manuscript. V.C. performed WES data analysis and validation and wrote the manuscript. C.K.B. contributed the electrophysiological studies and wrote the manuscript. 
L.S. and G.B. performed the homology modeling and structural analysis. A.C. and M.A. contributed to the WES data processing and analysis. E.F., S.P., M.L.D. and T.T.M.N. carried out the molecular screening and/or genotyping. P.G., G.C.K., V.L., D.M., L.D.V.N., P.T., S.M.W., B.D. and A.P. recruited and clinically characterized the study subjects, and collected the biological samples. P.M.C. performed WES data analysis, validation and genotyping. M.T. and K.K. conceived the project, analyzed and interpreted the data, and wrote the manuscript. All authors contributed to the final manuscript.

\section{COMPETING FINANCIAL INTERESTS}

The authors declare no competing financial interest.

\section{FIGURE LEGENDS}

Figure 1. Heterozygous missense mutations in $\mathrm{KCNH} 1$ and ATP6V1B2 in individuals with ZLS. (a) Pedigrees and segregation analysis of disease-associated KCNH1 and ATP6V1B2 variants. KCNH1 mutations are described according to the shorter isoform (NM_002238.3; NP_002229.1). na, not analyzed; +, wild-type allele; M, mutant allele; MM: two mutations in cis. (b) Cartoon of the KCNH1 channel, showing the location of affected amino acid residues in ZLS (colored dots). (c) Schematic view of the subunit structure of the V-ATPase. The catalytic V 1 complex consists of the A, B, C, D, E, F, G and H subunits. The $\mathrm{V}_{0}$ domain is membrane-embedded and composed of a characteristic c-ring structure, to which the a, $\mathrm{d}$ and e subunits are associated. Arginine 485 is highlighted by a blue dot. The color of the mutated residues (indicated by colored dots in $\mathbf{b}$ and $\mathbf{c}$ ) corresponds to the color of the KCNH1 and ATP6V1B2 missense mutations in a.

Figure 2. Clinical features of individuals with ZLS in whom a KCNH1 or ATP6V1B2 mutation was identified. (a-d) Facial phenotype of subjects with a KCNH1 mutation (a, 
subject 1; b, subject 3; c, subject 4; d, subject 5). Note central incisor in subject 3, and gingival enlargement in subjects 3 and 5. For detailed description of craniofacial dysmorphism see Supplementary Table 5. (e,g) Subject 1 has anonychia of the right great toe as well as hypoplastic nails of all other right toes and fingers of her left hand. (f,h) Radiographs of the left hand and left foot of subject 1 . She has hypoplastic terminal phalanges of the thumb, great toe and $3^{\text {rd }}$ to $5^{\text {th }}$ toes and aplastic terminal phalanx of the $2^{\text {nd }}$ toe. (i,j) Right hand and left foot of subject 2 . Aplastic nails of thumb and $1^{\text {st }}$ to $3^{\text {rd }}$ toes and hypoplastic nails of all other fingers and toes. (k,l) Absence of hypo/aplasia of nails and terminal phalanges in subject 4. (m,n) Subject 5 shows anonychia of thumbs and great toes and nail hypoplasia of the right $5^{\text {th }}$ finger and right $2^{\text {nd }}$ to $5^{\text {th }}$ toes. (o) Anonychia of the left great toe and hyponychia of all other toes in subject 6. (p-r) Facial appearance of subjects with an ATP6V1B2 mutation (p,q, subject 7 as neonate and at the age of 12 years, $\mathbf{r}$, subject 8). (s,t) Gingival enlargement in subject 7 and subject 8 . (u-x) Hands and feet of subjects 7 and 8. Anonychia of hands and feet occur in both subjects. (u,v) Subject 7 has aplastic terminal phalanges of $2^{\text {nd }}$ and $5^{\text {th }}$ left and $5^{\text {th }}$ right finger and of all toes except $1^{\text {st }} .(\mathbf{w}, \mathbf{x}) 2^{\text {nd }}$ to $4^{\text {th }}$ fingers, except the right $3^{\text {rd }}$ finger, and all toes of subject 8 are markedly shortened and have tapering ends. Hirsutism in subject $7(\mathbf{u}, \mathbf{v})$ and on the legs of subject $8(\mathbf{y})$. Consent for the publication of photographs was obtained for all patients.

Figure 3. Structural impact of ZLS-associated KCNH1 and ATP6V1B2 mutations. (a) Model of helices S5 and S6 of KCNH1 in their closed state, as viewed from the intracellular side of the membrane. Affected residues are indicated in yellow. $\mathrm{K}^{+}$is shown as a grey sphere. (b) Model of helices S5 and S6 of KCNH1 in their open state. The color code is the same as above. (c) Enlargement of the pore-closing region in the closed state. Atoms are reported as spheres to illustrate the steric hindrance of this region, which would hardly accommodate a larger residue, and particularly a charged amino acid, such as Arg, at position 
469. (d) Enlargement of the hydrophobic cluster formed by residues Leu352, Val356 and Ile467 (whose side chains are shown in sphere representation) in the open state. (e) Homology model of the B subunit of human V-ATPase (reported in ribbon representation) in the context of the $\mathrm{A}_{3} \mathrm{~B}_{3}$ hexamer of $E$. hirae ATPase (reported in surface representation, with A subunits colored in salmon and the B subunits in light blue). The complex is reported as seen from the membrane surface. One of the B subunits (colored in light blue) was substituted by the homology model of the B subunit of human V-ATPase (reported in ribbon representation). ATP analogs are shown in green, while Arg485 is represented in yellow. (f) Enlargement of the A/B interface. Arg485 and Asp507 are reported in stick representation. The C-terminal segment of the B subunit predicted to be destabilized by the Arg485Pro substitution is represented in yellow. The space-filling model of residues 485-511 is also shown, as a semitransparent white surface.

Figure 4. Voltage-dependent activation of human wild-type (WT) and mutant KCNH1 channels expressed in CHO cells. (a) Families of whole cell currents elicited with $2 \mathrm{~s}$ variable test pulses as indicated in the pulse protocol shown at the right below the current traces. For the mutant L352V, a more negative holding potential of $-100 \mathrm{mV}$ and test pulses starting from -120 mV were used. Transfection with the mutant G469R did not result in recordings of voltage-dependent $\mathrm{K}^{+}$currents $(\mathrm{n}=22)$. Zero current is indicated by dashed lines and arrowheads. (b) Mean ( \pm SEM) KCNH1 current amplitudes as function of the test pulse potential. Current amplitudes were normalized to the maximal amplitude recorded at +60 mV. Data points were connected by straight lines. The inset shows current amplitudes at $+40 \mathrm{mV}$ normalized to the mean wild-type current. (c) Mean ( \pm SEM) normalized whole cell conductance as function of the test pulse potential. Lines represent fourth-order Boltzmann functions fitted to the data points. Numbers of experiments are indicated in parentheses. (d) Mean (+ SEM) values of the potential of half maximal KCNH1 channel activation $\left(\mathrm{V}_{0.5}\right.$ 
activation), derived from fits to permeability data considering the Goldman-Hodgkin-Katz current equation. One way ANOVA with post hoc Bonferroni $t$-test yielded significant $(* * *$ : p $<0.001$ ) differences for all combinations except that indicated (n.s.: not significant). Parameters of fits to whole cell conductance and channel activation data are summarized in Supplementary Table 4.

Figure 5. Voltage-dependent activation of $\mathrm{KCNH1} \mathrm{K}^{+}$currents resulting from coexpression of wild-type (WT) with mutant KCNH1 channel subunits in CHO cells using a 1:1 cDNA ratio. (a) Representative whole cell currents resulting from G348R + WT coexpression. (b,c) Voltage dependence of normalized G348R + WT current amplitudes (b) and whole cell conductance (c). Means ( \pm SEM) of 6 experiments are shown. The grey line in c represents a fit of the data points using Equation 2 (Online Methods). Corresponding data for homomeric G348R and WT channels are shown for comparison as red and black lines, respectively. (d) Representative whole cell currents recorded from G469R + WT transfected cells. Zero current is indicated by a dashed line and arrowhead. (e,f) Voltage dependence of normalized G469R + WT current amplitudes (e), and whole cell conductance (f). Means ( \pm SEM) of 14 experiments are shown. The blue line in $\mathbf{f}$ represents a fit of the data points using Equation 3 (Online Methods). Corresponding data for homomeric WT channels are shown for comparison as black lines and the inset in $\mathbf{e}$ illustrates the mean current amplitude at +40 $\mathrm{mV}$ normalized to the mean wild-type current. Fit parameter are summarized in

\section{Supplementary Table 4.}

\section{REFERENCES}

1. Laband, P.F., Habib, G. \& Humphreys, G.S. Hereditary Gingival Fibromatosis. Report of an Affected Family with Associated Splenomegaly and Skeletal and Soft-Tissue Abnormalities. Oral. Surg. Oral. Med. Oral. Pathol. 17, 339-351 (1964). 
2. Alavandar, G. Elephantiasis gingivae. Report of an affected family with associated hepatomegaly, soft tissue \& skeletal abnormalities. J. All. India Dent. Assoc. 37, 349353 (1965).

3. Chacon-Camacho, O.F., Vazquez, J. \& Zenteno, J.C. Expanding the phenotype of gingival fibromatosis-mental retardation-hypertrichosis (Zimmermann-Laband) syndrome. Am. J. Med. Genet. 155A, 1716-1720 (2011).

4. Davalos, I.P. et al. Zimmermann-Laband syndrome: further clinical delineation. Genet. Couns. 16, 283-290 (2005).

5. Castori, M. et al. Clinical and genetic study of two patients with Zimmermann-Laband syndrome and literature review. Eur. J. Med. Genet. 56, 570-576 (2013).

6. Abo-Dalo, B. et al. Extensive molecular genetic analysis of the 3p14.3 region in patients with Zimmermann-Laband syndrome. Am. J. Med. Genet. 143A, 2668-2674 (2007).

7. Kim, H.G. et al. Candidate loci for Zimmermann-Laband syndrome at 3p14.3. Am. J. Med. Genet. 143, 107-111 (2007).

8. Stefanova, M. et al. Zimmermann-Laband syndrome associated with a balanced reciprocal translocation t(3;8)(p21.2;q24.3) in mother and daughter: molecular cytogenetic characterization of the breakpoint regions. Am. J. Med. Genet. A 117, 289-294 (2003).

9. Arikkath, J. \& Campbell, K.P. Auxiliary subunits: essential components of the voltage-gated calcium channel complex. Curr. Opin. Neurobiol. 13, 298-307 (2003).

10. Felix, R. Calcium channelopathies. Neuromolecular Med. 8, 307-318 (2006).

11. Kataoka, M., Kido, J., Shinohara, Y. \& Nagata, T. Drug-induced gingival overgrowth-a review. Biol. Pharm. Bull. 28, 1817-1821 (2005).

12. Abo-Dalo, B. et al. No mutation in genes of the WNT signaling pathway in patients with Zimmermann-Laband syndrome. Clin. Dysmorphol. 17, 181-185 (2008). 
13. Petrovski, S. et al. Genic intolerance to functional variation and the interpretation of personal genomes. PLoS Genet. 9, e1003709 (2013).

14. Samocha, K.E. et al. A framework for the interpretation of de novo mutation in human disease. Nat. Genet. 46, 944-950 (2014).

15. Bauer, C.K. \& Schwarz, J.R. Physiology of EAG K+ channels. J. Membr. Biol. 182, $1-15(2001)$.

16. Garg, V., Sachse, F.B. \& Sanguinetti, M.C. Tuning of EAG K(+) channel inactivation: molecular determinants of amplification by mutations and a small molecule. J. Gen. Physiol. 140, 307-324 (2012).

17. Thouta, S. et al. Proline scan of the HERG channel S6 helix reveals the location of the intracellular pore gate. Biophys. J. 106, 1057-1069 (2014).

18. Wynia-Smith, S.L., Gillian-Daniel, A.L., Satyshur, K.A. \& Robertson, G.A. hERG gating microdomains defined by S6 mutagenesis and molecular modeling. J. Gen. Physiol. 132, 507-520 (2008).

19. Veeramah, K.R. et al. Exome sequencing reveals new causal mutations in children with epileptic encephalopathies. Epilepsia 54, 1270-1281 (2013).

20. Yang, Y. et al. Multistate structural modeling and voltage-clamp analysis of epilepsy/autism mutation Kv10.2-R327H demonstrate the role of this residue in stabilizing the channel closed state. J. Neurosci. 33, 16586-16593 (2013).

21. Forgac, M. Vacuolar ATPases: rotary proton pumps in physiology and pathophysiology. Nat. Rev. Mol. Cell Biol. 8, 917-929 (2007).

22. Marshansky, V., Rubinstein, J.L. \& Gruber, G. Eukaryotic V-ATPase: novel structural findings and functional insights. Biochim. Biophys. Acta 1837, 857-879 (2014).

23. Arai, S. et al. Rotation mechanism of Enterococcus hirae V1-ATPase based on asymmetric crystal structures. Nature 493, 703-707 (2013). 
24. Fuster, D.G., Zhang, J., Xie, X.S. \& Moe, O.W. The vacuolar-ATPase B1 subunit in distal tubular acidosis: novel mutations and mechanisms for dysfunction. Kidney Int. 73, 1151-1158 (2008).

25. Martin, S. et al. Eag1 potassium channel immunohistochemistry in the CNS of adult rat and selected regions of human brain. Neuroscience 155, 833-844 (2008).

26. Hemmerlein, B. et al. Overexpression of Eag1 potassium channels in clinical tumours. Mol. Cancer 5, 41 (2006).

27. Pardo, L.A. \& Stühmer, W. The roles of $\mathrm{K}(+)$ channels in cancer. Nat. Rev. Cancer 14, 39-48 (2014).

28. Ouadid-Ahidouch, H. \& Ahidouch, A. K+ channel expression in human breast cancer cells: involvement in cell cycle regulation and carcinogenesis. J. Membr. Biol. 221, 16 (2008).

29. Weber, C. et al. Silencing the activity and proliferative properties of the human EagI Potassium Channel by RNA Interference. J. Biol. Chem. 281, 13030-13037 (2006).

30. Zhang, Y.Y. et al. BKCa and hEag1 channels regulate cell proliferation and differentiation in human bone marrow-derived mesenchymal stem cells. J. Cell. Physiol. 229, 202-212 (2014).

31. Ufartes, R. et al. Behavioural and functional characterization of Kv10.1 (Eag1) knockout mice. Hum. Mol. Genet. 22, 2247-2262 (2013).

32. Lipscombe, D., Helton, T.D. \& Xu, W. L-type calcium channels: the low down. J. Neurophysiol. 92, 2633-2641 (2004).

33. Correa, J.D. et al. Phenytoin-induced gingival overgrowth: a review of the molecular, immune, and inflammatory features. ISRN Dent. 2011, 497850 (2011).

34. Mantegazza, M. et al. Voltage-gated sodium channels as therapeutic targets in epilepsy and other neurological disorders. Lancet Neurol. 9, 413-424 (2010). 
35. Wynn, R.L. Calcium channel blockers and gingival hyperplasia--an update. Gen. Dent. 57, 105-107 (2009).

36. Harakalova, M. et al. Dominant missense mutations in ABCC9 cause Cantu syndrome. Nat. Genet. 44, 793-796 (2012).

37. van Bon, B.W. et al. Cantu syndrome is caused by mutations in ABCC9. Am. J. Hum. Genet. 90, 1094-1101 (2012).

38. Brownstein, C.A. et al. Mutation of KCNJ8 in a patient with Cantu syndrome with unique vascular abnormalities - support for the role of K(ATP) channels in this condition. Eur. J. Med. Genet. 56, 678-682 (2013).

39. Cooper, P.E. et al. Cantu syndrome resulting from activating mutation in the KCNJ8 gene. Hum. Mutat. 35, 809-813 (2014).

40. Nelson, R.D. et al. Selectively amplified expression of an isoform of the vacuolar H(+)-ATPase 56-kilodalton subunit in renal intercalated cells. Proc. Nat. Acad. Sci. USA 89, 3541-3545 (1992).

41. Puopolo, K. et al. Differential expression of the "B" subunit of the vacuolar H(+)ATPase in bovine tissues. J. Biol. Chem. 267, 3696-3706 (1992).

42. van Hille, B. et al. Heterogeneity of vacuolar H(+)-ATPase: differential expression of two human subunit B isoforms. Biochem. J. 303 (Pt 1), 191-198 (1994).

43. Yuan, Y. et al. De novo mutation in ATP6V1B2 impairs lysosome acidification and causes dominant deafness-onychodystrophy syndrome. Cell Res. 24, 1370-1373 (2014).

44. Jacquinet, A. et al. Temple-Baraitser syndrome: a rare and possibly unrecognized condition. Am. J. Med. Genet. 152A, 2322-2326 (2010).

45. White, S.M. \& Fahey, M. Report of a further family with dominant deafnessonychodystrophy (DDOD) syndrome. Am. J. Med. Genet. 155A, 2512-1515 (2011). 
46. Campeau, P.M. \& Hennekam, R.C. DOORS syndrome: Phenotype, genotype and comparison with Coffin-Siris syndrome. Am. J. Med. Genet. 166, 327-332 (2014).

47. Simons, C. et al. Mutations in the voltage-gated potassium channel gene KCNH1 cause Temple-Baraitser syndrome and epilepsy. Nat. Genet. 47, 73-77 (2015).

48. Mortensen, L.S. et al. KV10.1 opposes activity-dependent increase in Ca2+ influx into the presynaptic terminal of the parallel fibre - Purkinje cell synapse. J. Physiol. 593, 181-196 (2015).

49. Poëa-Guyon, S. et al. The V-ATPase membrane domain is a sensor of granular $\mathrm{pH}$ that controls the exocytotic machinery. J. Cell. Biol. 203, 283-298 (2013).

50. Mindell, J.A. Lysosomal acidification mechanisms. Ann. Rev. Physiol. 74, 69-86 (2012).

51. Steinberg, B.E. et al. A cation counterflux supports lysosomal acidification. J. Cell Biol. 189, 1171-1186 (2010).

52. Van Dyke, R.W. Acidification of rat liver lysosomes: quantitation and comparison with endosomes. Am. J. Physiol. 265, C901-917 (1993).

53. Kohl, T., Lorinczi, E., Pardo, L.A. \& Stühmer, W. Rapid internalization of the oncogenic K+ channel K(V)10.1. PloS One 6, e26329 (2011).

54. Ninkovic, M. et al. Physical and functional interaction of KV10.1 with Rabaptin-5 impacts ion channel trafficking. FEBS Lett. 586, 3077-3084 (2012). 


\section{Online Methods}

Subjects. 24 individuals with a phenotype fitting Zimmermann-Laband syndrome or suggestive of the disorder were included in this study. They were clinically assessed by experienced clinical geneticists and/or neurologists. Among them, five patients had previously been reported ${ }^{5,12}$. Clinical features are summarized in Table 1 and described in detail in Supplementary Table 5. Informed consent for DNA storage and genetic analyses was obtained from all subjects, and genetic studies were approved by all Institutional Review Boards of the participating institutions. Permission to publish photographs was given for all subjects shown in Figure 2.

Whole exome sequencing and data analysis. Targeted enrichment and massively parallel sequencing were performed on genomic DNA extracted from circulating leukocytes. Enrichment of the whole exome was performed using Nextera Enrichment kit (62 Mb) (Illumina) for subjects 1 and 7 and their parents, SureSelect AllExonV4 (51 M) (Agilent) for subject 4 and her parents, and Nimblegen SeqCap EZ Library v.3.0 (64 M) (Roche) for subjects 5 and 8 and parents of subject 8, according to the manufacturer's protocols. Each captured library was then loaded onto the HiSeq 2000 platform (Illumina). Raw image files were processed by CASAVA Software 1.7 or 1.8 (Illumina) for base calling, with default parameters, and the sequences of each individual were generated as 90bp, respectively. Reads were aligned to the human reference genome (UCSC GRCh37/hg19) using the Burrows-Wheeler Aligner (BWA V. 0.7.10) ${ }^{55}$. Low quality bases were trimmed from 3'-ends by applying the parameter 'q 15' when invoking BWA. Alignments belonging to the same sample were merged using the Picard tool (http://picard.sourceforge.net). Presumed PCR duplicates were removed using Picard's MarkDuplicates. The Genome Analysis Toolkit (GATK 3.2) ${ }^{56}$ was used for realignment of sequences encompassing INDELs and base quality recalibration.

SNPs and small INDELs were identified by means of the GATK Haplotype Caller and Unified Genotyper algorithms ${ }^{56}$, applying the following quality filters: variants with quality $>100$ and quality-by-depth score $>1.5$ were retained; variants below these thresholds or resulting from 4 or more reads having ambiguous mapping (this number being greater than 10\% of all aligned reads) were discarded. Only variants called by both algorithms were considered. Variants were filtered against available public (dbSNP138, 1,000 Genomes, Exome Variant Server and ExAC databases, only clinically associated variants and variants with unknown frequency or MAF $<0.1 \%$ were retained) and in-house databases. SnpEff toolbox v3.6 (ref. 57) was used to predict the functional impact of variants, which were filtered to retain only 
functionally relevant variants (i.e., missense, nonsense, coding indels and intronic variants at exon-intron junctions ranging from -5 to +5 ). Functional annotation of variants was performed by using snpEff v3.6 and dbNSFP2.5 (ref. 57,58).

Variant validation and mutation analysis. Sequence validation and segregation analyses for all the candidate variants, as well as mutation scanning of the entire KCNH1 (NM_172362.2 and NM_002238.3) and ATP6V1B2 (NM_001693.3) coding sequences, were performed by Sanger sequencing. Primer pairs designed to amplify the coding exons of the two genes and their intron boundaries (KCNH1, NC_000001.11, 210678315..211134115, complement; ATP6V1B2, NC_000008.11, 20197193..20221696) and PCR conditions are available on request. Amplicons were directly sequenced using the ABI BigDye Terminator Sequencing Kit (Applied Biosystems) and an automated capillary sequencer (ABI 3500; Applied Biosystems). Sequence electropherograms were analyzed using Sequence Pilot software (JSI Medical Systems, Kippenheim, Germany) and the Sequencing Analysis Software v.5.4 (Applied Biosystems). Genotyping was carried out with the PowerPlex ESX16 System Kit (Promega) and the AmpFl STR SGM plus Kit (Applied Biosystems) to confirm paternity and maternity. The effects of predicted amino acid substitutions were assessed with Radial Support Vector Machine (RadialSVM) ${ }^{58}$ and Combined Annotation Dependent Depletion (CADD) ${ }^{59}$.

Haplotype determination. Exon 7 of $K C N H 1$ and adjacent intronic sequences were amplified from genomic DNA of subject 2. The PCR product was cloned into the pCR2.1 TOPO TA Cloning Vector (Invitrogen). 16 individual E.coli clones were picked and subjected to colony PCR and Sanger sequencing.

Structural analyses. Homology models of helices S5 to S6 of the potassium voltage-gated channel, subfamily H member 1 (KCNH1) and the B subunit (isoform 2) of the human vacuolar ATPase, ATP6V1B2, based on the available crystallographic structures of homologous proteins. In the case of KCNH1, the sequence identity with available experimental structures was relatively low (15-30\%), and no suitable templates were available for the whole S1-S6 sequence. Comparison of these structures, however, documented that even proteins with very low homology in sequence are characterized by an extremely similar conformation and relative arrangement of the membrane-embedded segments corresponding to helix S5 (residues 350370 in KCNH1), and the pore forming segment and helix S6 (residues 424-471). The only significant difference between structures was represented by the presence of a kink in S6 helices 
containing a conserved PVP motif, which is absent in the KCNH1 sequence ${ }^{17}$. The high similarity between the structures of helices S5 and S6 in proteins lacking the PVP motif supports the validity of obtaining a homology model for this region, where most of the identified diseasecausing mutations are located (hereafter, position of residues refer to the shorter KCNH1 isoform). Two models of the helix S5-to-helix S6 region (residues 350-471), referring to the open and closed channel states, were obtained by using the SWISS-MODEL server ${ }^{60}$. For the open state, the KvAP voltage-dependent $\mathrm{K}^{+}$channel from A. pernix (PDB code 1orq, 23\% identity) served as a template for both the homology modeling and the quaternary structure assembly. For the closed state, the structure of the $\mathrm{K}^{+}$complex of the NaK Channel (PDB code 2ahz, 29\% identity) was used as template, which was assembled based on the structure of the voltage-gated $\mathrm{K}^{+}$channel of $L$. monocytogenes in its closed state (PDB code $4 \mathrm{~h} 33$ ). All these templates lack the kink-inducing PVP motif.

For ATP6V1B2, a homology model was generated by using the I-Tasser server ${ }^{61}$ and templates with sequence identities ranging from 55\% to 59\% (PDB codes 3gqb, 3vr6, 2c61, $3 \mathrm{vr} 4$, and 3a5c). The model was fitted on the structure of the $\mathrm{A}_{3} \mathrm{~B}_{3}$ complex determined crystallographically for the E. hirae ATPase bound to a non-hydrolyzable ATP analog (PDB code 3vr3).

Molecular graphics were developed with the UCSF Chimera software ${ }^{62}$.

Site-directed mutagenesis. KCNH1 single mutations p.I467V, p.S325Y, p.G348R, p.L352V, p.V356L, p.G469R, and the two mutations p.S325Y/p.V356L were introduced into the cDNA with the QuikChange Site-Directed Mutagenesis Kit (Agilent Technologies). All constructs were sequenced for integrity.

Heterologous KCNH1 expression in CHO cells and Xenopus oocytes. Chinese hamster ovary (CHO) cells were transfected with wild-type (WT) or mutant human KCNH1 (hEAG1, isoform 1) cDNA and cDNA encoding EGFP-N1 (Clontech) using LipofectAMINE 2000 (Invitrogen) as described previously ${ }^{63}$. Final concentration of channel cDNA cloned into the pcDNA3 vector (Invitrogen) was $200 \mathrm{ng} / \mathrm{ml}$. For WT and G469R co-expression, $200 \mathrm{ng} / \mathrm{ml}$ of each plasmid was used. For co-expression experiments of WT and G348R, CHO cells were microinjected with a Transjector 5246 (Eppendorf, Hamburg, Germany) with equal amounts of both channel cDNA containing plasmids (17 ng/ $\mu$ l) together with EGFP-N1 as described previously ${ }^{63}$. 
Xenopus laevis oocytes were collected under anesthesia (Tricain $1.2 \mathrm{~g} / \mathrm{l}$ ) and the follicular tissue was removed by collagenase A (Roche, Basel, Switzerland). Before and after injection of cRNA, oocytes were kept at $18^{\circ} \mathrm{C}$ in medium containing $75 \mathrm{mM} \mathrm{NaCl}, 5 \mathrm{mM}$ Na-pyruvate, 2 $\mathrm{mM} \mathrm{KCl}, 2 \mathrm{mM} \mathrm{CaCl} 2,1 \mathrm{mM} \mathrm{MgCl}_{2}$ and $5 \mathrm{mM}$ HEPES; $\mathrm{pH}$ adjusted to 7.5 with $\mathrm{NaOH}$, supplemented with $50 \mathrm{mg} / \mathrm{l}$ gentamicin. Xenopus laevis oocytes were injected with cRNA encoding either KCNH1 wild-type (5 ng / $50 \mathrm{nl}$ ) channel or the KCNH1 mutant G469R (5 ng / 50 nl) using a Nanoliter 2000 microinjector (World Precision Instruments, Berlin, Germany). For co-expression experiments, the $50 \mathrm{nl}$ injection volume contained $5 \mathrm{ng}$ of each KCNH1 cRNA. Oocytes were used for experiments 2 days after injection.

Electrophysiology. Patch-clamp experiments were performed 5-30 hours after CHO cell transfection or microinjection in the conventional whole-cell configuration of the patch-clamp technique. The external Ringer solution contained $140 \mathrm{mM} \mathrm{NaCl}, 5 \mathrm{mM} \mathrm{KCl}, 0.8 \mathrm{mM} \mathrm{MgCl} 2$, $1 \mathrm{mM} \mathrm{CaCl}_{2}, 5 \mathrm{mM}$ glucose and $10 \mathrm{mM}$ HEPES; pH adjusted to 7.4 with $\mathrm{NaOH}$. The pipette solution contained $140 \mathrm{mM} \mathrm{KCl}, 2 \mathrm{mM} \mathrm{MgCl}_{2}, 1 \mathrm{mM} \mathrm{CaCl}_{2}, 2.5 \mathrm{mM}$ EGTA and $10 \mathrm{mM}$ HEPES; pH adjusted to 7.3 with $\mathrm{KOH}$. Patch pipettes had resistances of 1.5 to $3 \mathrm{M} \Omega$. The access resistance ranged from 1.8 to $5 \mathrm{M} \Omega$ and series resistance was compensated for by at least $70 \%$. Signals were compensated for both fast and slow capacity transients, low-pass filtered at 10 and $3 \mathrm{kHz}$ and digitized at a sample interval of 0.2 - $1 \mathrm{~ms}$. Data were not corrected for the liquid junction potential error of about $4 \mathrm{mV}$ and no leak subtraction was performed.

An EPC-9 patch clamp amplifier was used in combination with the PULSE stimulation and data acquisition software (HEKA Elektronik, Lambrecht, Germany). The standard activation protocol consisted of variable 2-s test pulses every $10 \mathrm{~s}$ from a holding potential of $80 \mathrm{mV}$. A more negative holding potential of $-100 \mathrm{mV}$ was necessary for the L352V KCNH1 channel construct due to its considerable conductance at $-80 \mathrm{mV}$. All test pulses were followed by a constant hyperpolarizing pulse to $-100 \mathrm{mV}$. Additional pulse protocols are depicted in the figures. The experiments were performed at room temperature $\left(20-21^{\circ} \mathrm{C}\right)$.

Xenopus oocyte currents were recorded by two-electrode voltage-clamp technique using a Turbo TEC 03 amplifier (npi electronic GmbH, Tamm, Germany) and PATCHMASTER acquisition software (HEKA Elektronik). The external solution contained $91 \mathrm{mM} \mathrm{NaCl}, 5 \mathrm{mM}$ $\mathrm{KCl}, 1 \mathrm{mM} \mathrm{MgCl}$, $1 \mathrm{mM} \mathrm{CaCl}_{2}$ and $5 \mathrm{mM}$ HEPES; $\mathrm{pH}$ adjusted to 7.4 with $\mathrm{NaOH}$. Pipettes were filled with $3 \mathrm{M} \mathrm{KCl}$ solution. Experiments were performed at room temperature. 
Data analysis. Patch-clamp data processing was performed with PulseFit 8.65 (HEKA), Excel (Microsoft Corp.) and Sigmaplot 11.0 (Systat Software). Current amplitudes were determined as mean values during the last period of the 2-s test pulses or as maximal current amplitude for slightly inactivating current traces. The manifestation of KCNH1 channel inactivation at the most positive potentials was variable for all channel constructs. Experiments with pronounced inactivation at a test pulse potential of $+60 \mathrm{mV}$ were not included in the data analysis. Due to a high variability in current amplitudes for each channel construct, current amplitudes of individual experiments were normalized to the maximal current amplitude recorded during the test pulse to $+60 \mathrm{mV}$. Conductance-voltage $(\mathrm{G}-\mathrm{V})$ relationships were determined based on the equation:

$\mathrm{G}=\mathrm{I}_{\mathrm{norm}} /\left(\mathrm{V}-\mathrm{V}_{\mathrm{rev}}\right)$,

(Equation 1)

where $\mathrm{I}_{\text {norm }}$ is the normalized current amplitude at the test pulse potential $\mathrm{V}$, and $\mathrm{V}_{\text {rev }}$ is the current reversal potential, determined from the resting membrane potential measured in the current-clamp mode or as intrapolated value of the current reversal potential derived from deactivation protocols. Only for the experiments with wild-type KCNH1 channels, a fixed value of $-70 \mathrm{mV}$ was used. G-V relationships were analyzed with a fourth-order Boltzmann function of the form:

$\mathrm{G} / \mathrm{G}_{\max }=1 /\left(\left(1+\exp \left(-\left(\mathrm{V}-\mathrm{V}^{\prime}\right) / \mathrm{s}\right)\right)^{4}\right)$

(Equation 2)

where $G / G_{\max }$ is the normalized whole cell conductance at a test pulse potential V. The voltage dependence is defined by $V^{\prime}$ (6.25\% of the maximal conductance) and the slope factor $s . \mathrm{V}_{0.5}$ conductance values in Supplementary Table $\mathbf{4}$ are the potentials where the above function has a value of 0.5 .

Conductance data resulting from co-expression of WT and G469R channel constructs were not well fitted by the fourth order Boltzmann function, indicating more than one channel population with differences in the voltage dependence of activation. These data were fitted by the sum of a fourth order Boltzmann function (to allow direct comparison with WT channel properties), a first order Boltzmann function and a leak conductance component:

$\mathrm{G} / \mathrm{G}_{\max }=\mathrm{a} /\left(\left(1+\exp \left(-\left(\mathrm{V}-\mathrm{V}^{\prime}\right) / \mathrm{s}\right)\right)^{4}\right)+\mathrm{b} /\left(1+\exp \left(-\left(\mathrm{V}-\mathrm{V}_{0.5}\right) / \mathrm{k}\right)\right)+\mathrm{c}$,

(Equation 3)

where $a, b$ and $c$ indicate the relative contributions of the three conductance components, with $V_{0.5}$ as the potential of half-maximal conductance and $k$ as the slope factor for component $b$.

The voltage dependence of KCNH1 channel activation (or the relative open probability of the channels) was assessed by describing normalized $\mathrm{K}^{+}$current values according to a 
simplified Goldman-Hodgkin-Katz current equation ${ }^{64,65}$ to account for unequal $\mathrm{K}^{+}$ concentrations in the external and internal solution:

$\mathrm{I}_{\mathrm{K}}=\mathrm{P}_{\mathrm{K}} \mathrm{V}\left(\left(1-\exp \left(-\left(\mathrm{V}-\mathrm{V}_{\text {rev }}\right) / 25\right)\right) /(1-\exp (-\mathrm{V} / 25))\right)$

(Equation 4)

Resulting relative $\mathrm{P}_{\mathrm{K}}$ values for the membrane`s permeability to $\mathrm{K}^{+}$were fitted with a firstorder Boltzmann function or, for co-expression of WT and G469R KCNH1 channel subunits, with the sum of two first-order Boltzmann functions analogous to Equation 3:

$\mathrm{P}_{\mathrm{K}} / \mathrm{P}_{\mathrm{K}, \max }=\mathrm{a} /\left(1+\exp \left(-\left(\mathrm{V}-\mathrm{V}_{\mathrm{a} ; 0.5}\right) / \mathrm{k}_{\mathrm{a}}\right)\right)+\mathrm{b} /\left(1+\exp \left(-\left(\mathrm{V}^{-} \mathrm{V}_{\mathrm{b} ; 0.5}\right) / \mathrm{k}_{\mathrm{b}}\right)\right)+\mathrm{c} . \quad$ (Equation 5)

Fit results to whole cell conductance data and permeability data are given in Supplementary

Table 4.

Statistics. Experimental data are given as means \pm SEM, with $n$ representing the number of experiments from different cells. One way ANOVA with post hoc Bonferroni $t$-test or student's two-tailed unpaired $t$ test were used to test for significance as indicated with $\alpha=0.05$.

\section{REFERENCES:}

55. Li, H. \& Durbin, R. Fast and accurate short read alignment with Burrows-Wheeler transform. Bioinformatics 25, 1754-1760 (2009).

56. McKenna, A. et al. The Genome Analysis Toolkit: a MapReduce framework for analyzing next-generation DNA sequencing data. Genome Res. 20, 1297-1303 (2010).

57. Cingolani, P. et al. A program for annotating and predicting the effects of single nucleotide polymorphisms, SnpEff: SNPs in the genome of Drosophila melanogaster strain w1118; iso-2; iso-3. Fly 6, 80-92 (2012).

58. Liu, X., Jian, X. \& Boerwinkle, E. dbNSFP v2.0: a database of human non-synonymous SNVs and their functional predictions and annotations. Hum. Mutat. 34, E2393-2402 (2013).

59. Kircher, M. et al. A general framework for estimating the relative pathogenicity of human genetic variants. Nat. Genet. 46, 310-315 (2014).

60. Biasini, M. et al. SWISS-MODEL: modelling protein tertiary and quaternary structure using evolutionary information. Nucleic Acids Res. 42, W252-258 (2014).

61. Roy, A., Kucukural, A. \& Zhang, Y. I-TASSER: a unified platform for automated protein structure and function prediction. Nat. Protoc. 5, 725-38 (2010).

62. Pettersen, E.F. et al. UCSF Chimera--a visualization system for exploratory research and analysis. J. Comput. Chem. 25, 1605-1612 (2004). 
63. Schuster, A.M., Glassmeier, G. \& Bauer, C.K. Strong activation of ether-a-go-go-related gene $1 \mathrm{~K}+$ channel isoforms by NS1643 in human embryonic kidney 293 and Chinese hamster ovary cells. Mol. Pharmacol. 80, 930-942 (2011).

64. Clay, J.R. Determining k channel activation curves from k channel currents often requires the goldman-hodgkin-katz equation. Front. Cell. Neurosci. 3, 20 (2009).

65. Schönherr, R. et al. Individual subunits contribute independently to slow gating of bovine EAG potassium channels. J. Biol. Chem. 274, 5362-5369 (1999). 


\section{SUPPLEMENTARY INFORMATION}

\section{Mutations in KCNH1 and ATP6V1B2 cause Zimmermann-Laband syndrome}

Fanny Kortüm ${ }^{1,21}$, Viviana Caputo ${ }^{2,21}$, Christiane K. Bauer ${ }^{3,21}$, Lorenzo Stella ${ }^{4}$, Andrea Ciolfi $^{2,5}$, Malik Alawi ${ }^{6,7,8}$, Gianfranco Bocchinfuso ${ }^{4}$, Elisabetta Flex ${ }^{5}$, Stefano Paolacci ${ }^{2,5}$, Maria Lisa Dentici ${ }^{9}$, Paola Grammatico ${ }^{10}$, Georg Christoph Korenke ${ }^{11}$, Vincenzo Leuzzi $^{12}$, David Mowat ${ }^{13,14}$, Lal D. V. Nair ${ }^{15}$, Thi Tuyet Mai Nguyen ${ }^{16}$, Patrick Thierry ${ }^{17}$, Susan M. White ${ }^{18,19}$, Bruno Dallapiccola ${ }^{9}$, Antonio Pizzuti² ${ }^{2}$ Philippe M. Campeau ${ }^{20}$, Marco Tartaglia ${ }^{5,9,22}$, Kerstin Kutsche $e^{1,22}$

${ }^{1}$ Institute of Human Genetics, University Medical Center Hamburg-Eppendorf, Hamburg, Germany.

${ }^{2}$ Dipartimento di Medicina Sperimentale, Università La Sapienza, Rome, Italy.

${ }^{3}$ Department of Cellular and Integrative Physiology, University Medical Center HamburgEppendorf, Hamburg, Germany.

${ }^{4}$ Dipartimento di Scienze e Tecnologie Chimiche, Università “Tor Vergata”, Rome, Italy. ${ }^{5}$ Dipartimento di Ematologia, Oncologia e Medicina Molecolare, Istituto Superiore di Sanità, Rome, Italy.

${ }^{6}$ University Medical Center Hamburg-Eppendorf, Bioinformatics Service Facility, Hamburg, Germany.

${ }^{7}$ Center for Bioinformatics, University of Hamburg, Hamburg, Germany.

${ }^{8}$ Heinrich-Pette-Institute, Leibniz-Institute for Experimental Virology, Virus Genomics, Hamburg, Germany.

${ }^{9}$ Ospedale Pediatrico Bambino Gesù- IRCSS, Rome, Italy.

${ }^{10}$ Dipartimento di Medicina Molecolare, Università La Sapienza, Ospedale San CamilloForlanini, Rome, Italy.

${ }^{11}$ Zentrum für Kinder- und Jugendmedizin, Neuropädiatrie, Klinikum Oldenburg gGmbH, Oldenburg, Germany.

${ }^{12}$ Dipartimento di Pediatria e Neuropsichiatria Infantile, Università La Sapienza, Rome, Italy.

${ }^{13}$ Department of Medical Genetics, Sydney Children’s Hospital, Sydney, Australia.

${ }^{14}$ School of Women's and Children's Health, UNSW Medicine, University of New South Wales, Sydney, Australia. 
${ }^{15}$ Department of Pediatrics, Saveetha Medical College and Hospital, Saveetha University, Chennai, Tamil Nadu, 600077, India.

${ }^{16}$ Sainte-Justine Hospital Research Center, University of Montreal, Montreal, QC, Canada.

${ }^{17}$ Service de Pédiatrie, CHI Haute-Saône, Vesoul, France.

${ }^{18}$ Victorian Clinical Genetics Services, Murdoch Childrens Research Institute, Royal

Children’s Hospital, Melbourne, Australia.

${ }^{19}$ Department of Paediatrics, University of Melbourne, Australia.

${ }^{20}$ Department of Pediatrics, Sainte-Justine Hospital, University of Montreal, Montreal, QC, Canada.

${ }^{21}$ These authors contributed equally to this project.

${ }^{22}$ These authors jointly directed this project.

\section{Corresponding authors:}

Kerstin Kutsche, PhD

Institute of Human Genetics

University Medical Center Hamburg-Eppendorf

Martinistraße 52

20246 Hamburg, Germany

phone: +49 40 741054597, fax: +49 40 741055138, email: kkutsche@uke.de

Marco Tartaglia, PhD

Dipartimento di Ematologia, Oncologia e Medicina Molecolare

Istituto Superiore di Sanità

Viale Regina Elena, 299

00161 Rome, Italy

phone: +39 06 49902569, fax: + 3906 49387143, email: marco.tartaglia@iss.it 


\section{KCNH1}
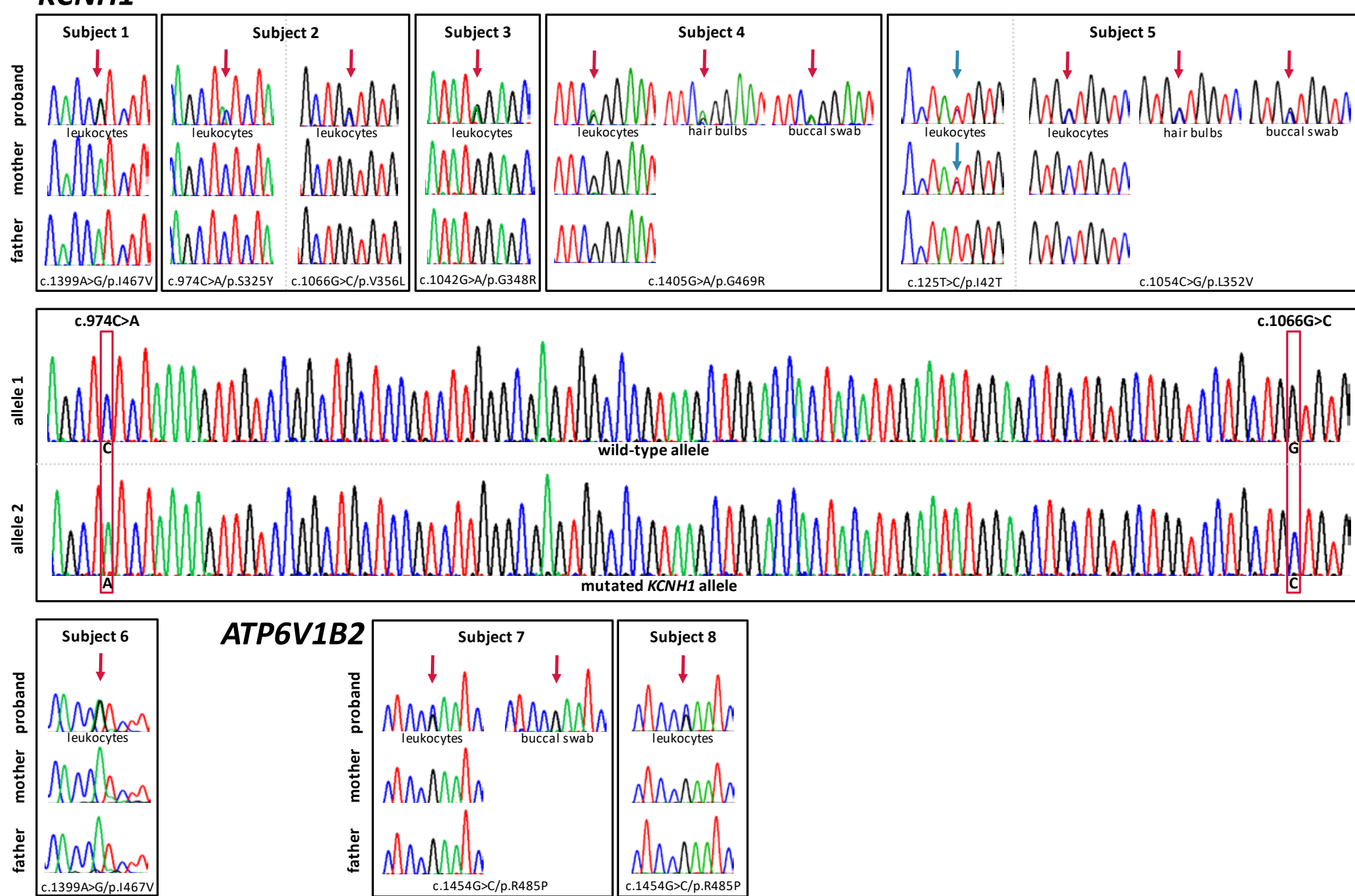

c.1405G>A/p.G469R c. $1066 \mathrm{G}>\mathrm{C}$

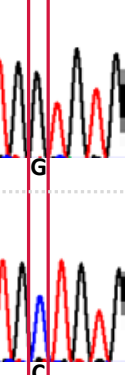
mutated KCNH1 allele

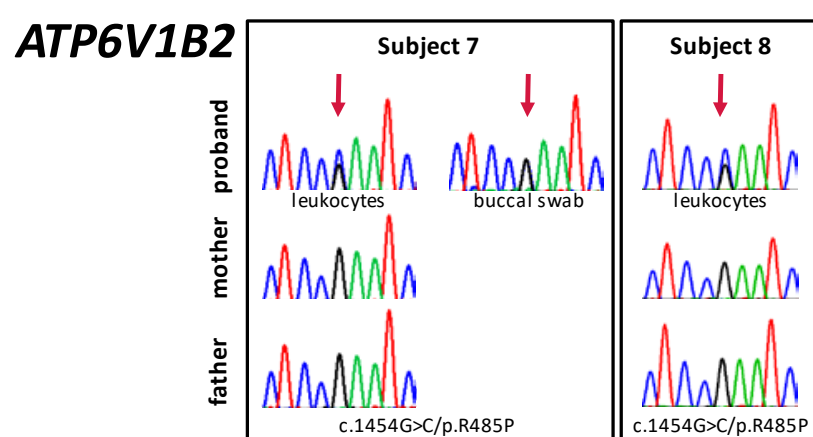

Supplementary Figure

1. Sequence electropherograms showing the de novo origin of the identified $K C N H 1$ and ATP6V1B2 missense mutations in subjects 1-8 (upper and lower panels, indicated by red arrows). The heterozygous state of three mutations was documented

peripheral leukocytes, hair bulb and/or buccal cells of subjects 4,5 and 7 indicating germline origin. An additional previously annotated (ExAC database) heterozygous $K C N H 1$ variant, c. $125 \mathrm{~T}>\mathrm{C} / \mathrm{p} .142 \mathrm{~T}$, was present in subject 5 and his healthy mother (indicated by blue arrows). By cloning the KCNH1 exon 7-containing amplicon of subject 2 followed by sequencing we determined the haplotypes and found that the two identified de novo changes c.974C $>\mathrm{A}$ and c.1066G $>\mathrm{C}$ are in cis (wild-type allele and mutated $K C N H 1$ allele in the middle panel; mutated nucleotides are framed). 


\section{Supplementary Figure 2}

KCNH1_human KCNH1_chicken KCNH1_cattle $\mathrm{KCNH} 1$ _chimpanzee $\mathrm{KCNH} 1$ macaque KCNH1_mouse $\mathrm{KCNH1}$ 1_rat KCNH1_zebrafish KCNH1_C.elegans $\mathrm{KCNH} 1$ fruit fly KCNH1_mosquito

KCNH1_human $\mathrm{KCNH} 1$ _chicken KCNH1_cattle KCNH1_chimpanzee KCNH1_macaque KCNH1_mouse KCNH1_rat KCNH1_zebrafish $\mathrm{KCNH} 1$ C.elegans $\mathrm{KCNH} 1$ fruit fly KCNH1_mosquito
325

348352356

GISSLFSSLKVVRLLRLGRVARKLDHYIEYGAAVLVLLVCVFGLAAHWMAC GISSLFSSLKVVRLLRLGRVARKLDHYIEYGAAVLVLLVCVFGLAAHWLAC GISSLFSSLKVVRLLRLGRVARKLDHYIEYGAAVLVLLVCVFGLAAHWMAC GISSLFSSLKVVRLLRLGRVARKLDHYIEYGAAVLVLLVCVFGLAAHWMAC GISSLFSSLKVVRLLRLGRVARKLDHYIEYGAAVLVLLVCVFGLAAHWMAC GISSLFSSLKVVRLLRLGRVARKLDHYIEYGAAVLVLLVCVFGLAAHWMAC GISSLFSSLKVVRLLRLGRVARKLDHYIEYGAAVLVLLVCVFGLAAHWMAC GISSLFSSLKVVRLLRLGRVARKLDHYIEYGAAVLVLLVCVFGLAAHWLAC RIGSLFSALKVVRLLRLGRVARKLDNYLEYGAATLLLLLCAYVIVAHWLAC GIGSLFSALKVVRLLRLGRVVRKLDRYLEYGAAMLILLLCFYMLVAHWLAC GIGSLFSALKVVRLLRLGRVVRKLDRYLEYGAAMLILLLCFYMLVAHWLAC

\section{9}

IGSLLYATIFGNVTTIFQQ IGSLLYATIFGNVTTIFQQ IGSLLYATIFGNVTTIFQQ IGSLLYATIFGNVTTIFQQ IGSLLYATIFGNVTTIFQQ IGSLLYATIFGNVTTIFQQ IGSLLYATIFGNVTTIFQQ IGSLLYATIFGNVTNIFQQ ISALLYAAIFGHMTTIIQQ IAALLYATIFGHVTTIIQQ IAALLYATIFGHVTTIIQQ

ATP6V1B2_human ATP6V1B2_chimpanzee ATP6V1B2_macaque ATP6V1B2_wolf ATP6V1B2_cattle ATP6V1B2_mouse ATP6V1B2_rat ATP6V1B2_chicken ATP6V1B2_zebrafish ATP6V1B2_fruit fly ATP6V1B2_mosquito ATP6V1B2_C.elegans ATP6V1B2_yeast ATP6V1B2_K. lactis ATP6V1B2_E.gossypii ATP6V1B2_fission yeast ATP6V1B2_M. oryzae ATP6V1B2_N.crassa ATP6V1B2_arabidopsis ATP6V1B2_rice ATP6V1B2_clawed frog
485

ENRTVFETLDIGWQLLRIFPKEMLKRIPQSTLSEFYPR ENRTVFETLDIGWQLLRIFPKEMLKRIPQSTLSEFYPR ENRTVFETLDIGWQLLRIFPKEMLKRIPQSTLSEFYPR ENRTVYETLDIGWQLLRIFPKEMLKRIPQSTLSEFYPR ENRTVYETLDIGWQLLRIFPKEMLKRIPQSTLSEFYPR ENRTVYETLDIGWQLLRIFPKEMLKRIPQSTLSEFYPR ENRTVYETLDIGWQLLRIFPKEMLKRIPQSTLSEFYPR ENRTVYETLDIGWQLLRIFPKEMLKRIPQTTLAEFYPR ENRTVFETLDIGWQLLRIFPKEMLKRIPQSTLAEFYPR ENRTVFESLDIGWQLLRIFPKEMLKRIPASILAEFYPR ENRTVFESLDIGWQLLRIFPKEMLKRIPASILAEFYPR ENRTIVESLNIGWELLRIFPREMLKRIPETLLEKYYKR EDRTVFESLDQAWSLLRIYPKEMLNRISPKILDEFYDR EDRTVFESLDQAWSLLRIYPKEMLNRISPKILDEFYDR ENRTIFESLDHAWSLLRIYPKEMLNRISPKILDEFYNR ENRTIFETLDLAWSLLRIFPREMLTRIPKKILDQYYSR EARTIYESLDLAWSLLRIYRKDMLNRIPAKIINEYYQR ESRTIFESLDLAWSLLRIYRKDMLNRIPKKIIDEFYSR DTRNIFQSLDLAWTLLRIFPRELLHRIPAKTLDQFYSR DTRNIFQSLDLAWTLLRIFPRELLHRIPAKTLDQYYSR DNRTVYETLDIGWQLLRIFPKELLKRIPQSTLAEFYPR

Supplementary Figure 2 Alignment of the regions flanking the detected missense variants in orthologous proteins, showing the evolutionary conservation of amino acids S325, G348, L352, V356, 1467 and G469 in human KCNH1 (NP_002229.1) and R485 in human ATP6V1B2 (NP_001684.2). Multiple alignments were gathered from http://www.ncbi.nlm.nih.gov/homologene/. Conserved residues have a red and non-conserved a grey background. Amino acid sequence alignments demonstrate high (S325 and V356 in human KCNH1) or complete evolutionary conservation (G348, L352, 1467, G469 in human KCNH1 and R485 in human ATP6V1B2) of the altered residues. 


\section{Supplementary Figure 3}

a

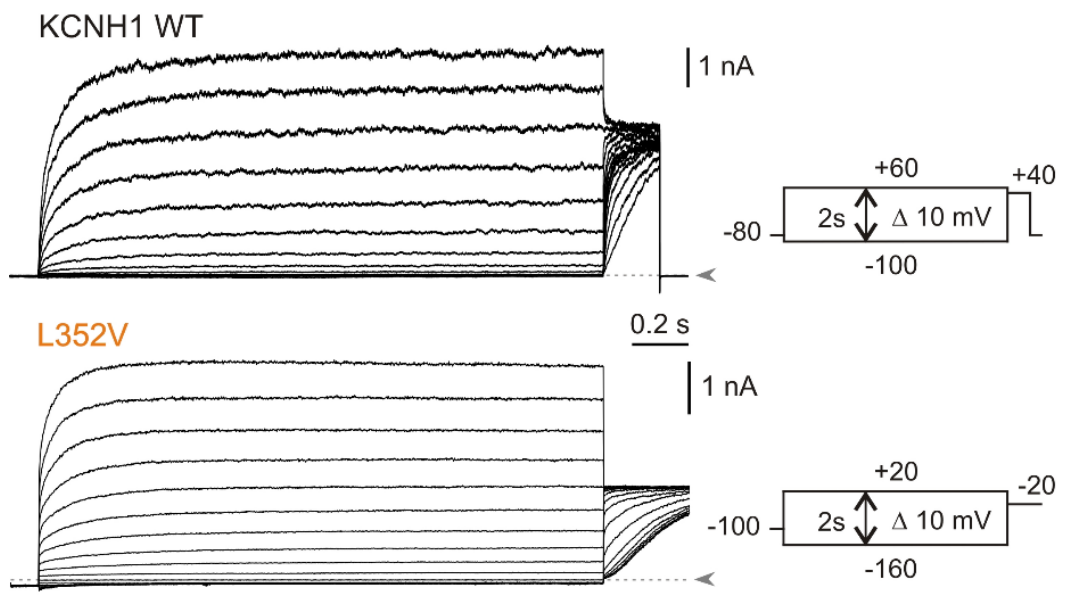

b

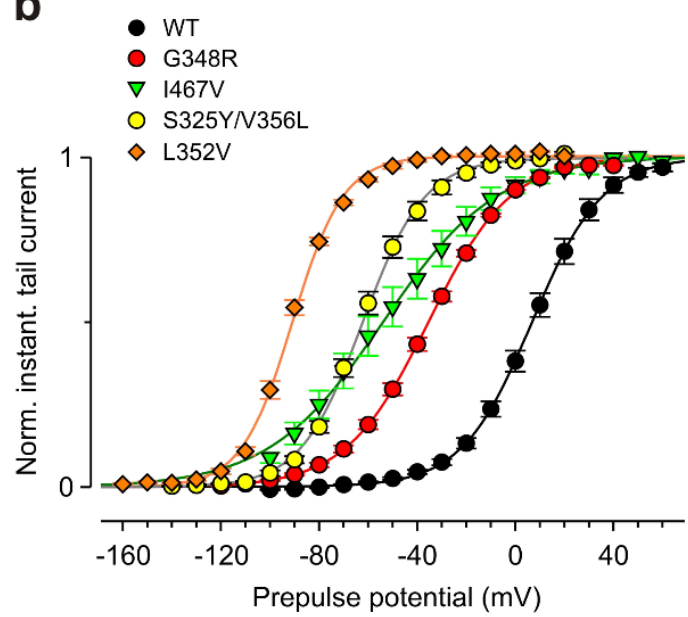

C

\begin{tabular}{|l|c|c|c|c|c|}
\hline & KCNH1 WT & G348R & $1467 \mathrm{~V}$ & S325Y/N356L & L352V \\
\hline$n$ & 9 & 8 & 9 & 13 & 6 \\
\hline $\mathrm{V}_{0.5 \text { activation }}[\mathrm{mV}]$ & $8.3 \pm 2.3$ & $-35.9 \pm 1.6^{* * *}$ & $-53.6 \pm 5.5^{\star * *}$ & $-61.3 \pm 1.8^{* * *}$ & $-90.9 \pm 0.9^{* * *}$ \\
\hline$k[\mathrm{mV}]$ & $14.7 \pm 0.6$ & $16.7 \pm 0.4$ & $20.9 \pm 0.8^{* * *}$ & $12.2 \pm 0.6^{*}$ & $10.3 \pm 0.4^{\star * *}$ \\
\hline
\end{tabular}

Supplementary Figure 3 Voltage dependence of wild-type and mutant KCNH1 channel activation.

(a) KCNH1 channels were expressed in CHO cells and families of WT and L352V current traces recorded with the depicted pulse protocols are shown. Zero current is indicated by dashed lines and arrowheads. (b) Mean ( \pm SEM) normalized instantaneous tail current amplitudes as function of the preceding test pulse potential. Lines represent first-order Boltzmann functions fitted to the data points. Voltage dependence of channel activation was analyzed from instantaneous tail current measurements at $+40 \mathrm{mV}$ (for KCNH1 WT and I467V for all experiments and for G348R and S325Y/V356L for four experiments each) or at $-20 \mathrm{mV}$ (for L352V, G348R and S325Y/V356L). No significant differences were found between the potentials for half maximal G348R or S325Y/V356L channel activation determined with the two different constant pulse potentials. (c) Table with means \pm SEM of the potential and the slope factor $k$ derived from fits of first-order Boltzmann functions to the normalized instantaneous tail current amplitudes of the individual experiments. $n$ : number of experiments; ${ }^{*},{ }^{* * *}$ : significantly different from WT with $p<0.05$ and $p<0.001$, respectively. Values were tested for significant differences compared to WT data with one way ANOVA and post hoc Bonferroni $t$-test. 


\section{Supplementary Figure 4}

a Activation kinetics
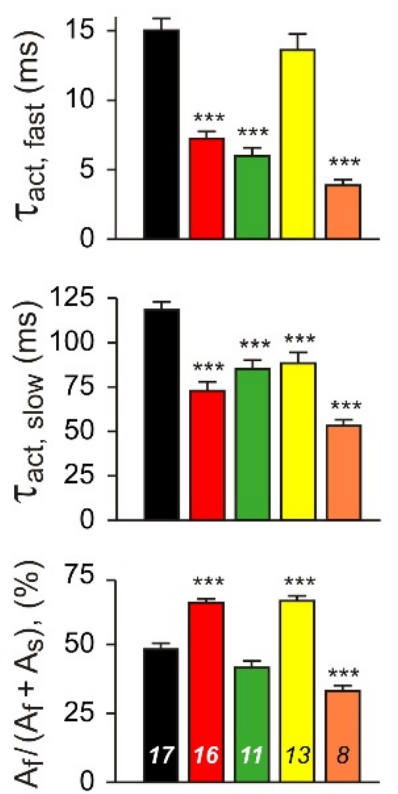

b

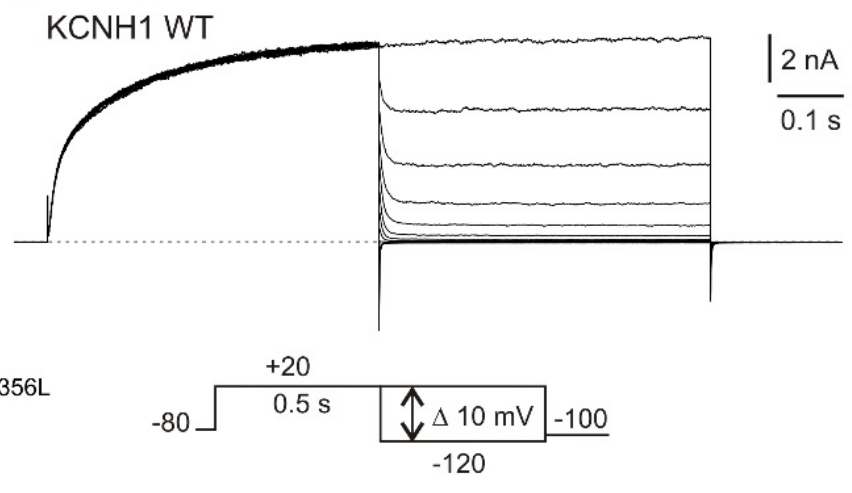

G348R

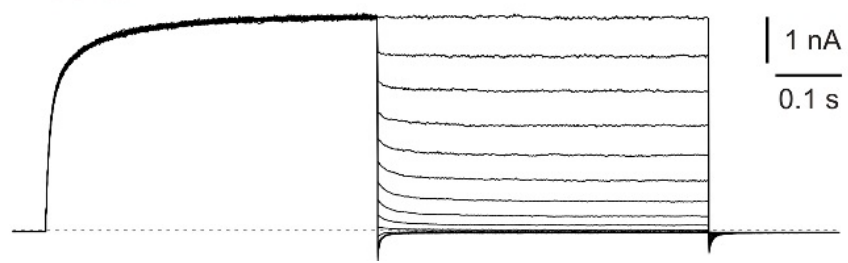

C Deactivation kinetics
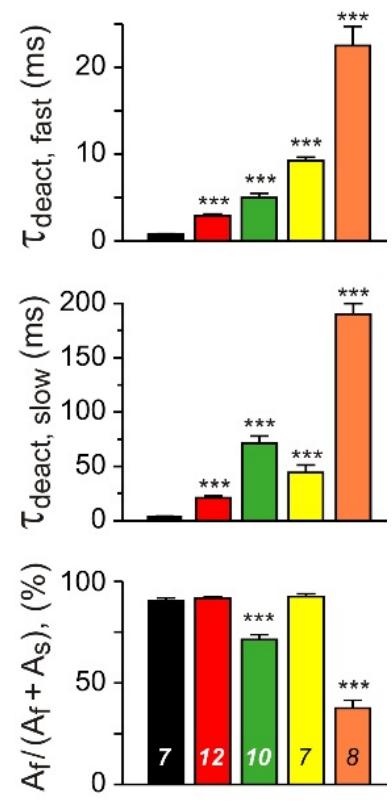

Supplementary Figure 4 Analysis of activation and deactivation kinetics of wild-type and mutant KCNH1 channels expressed in $\mathrm{CHO}$ cells.

(a) The time course of channel activation was analyzed at $+40 \mathrm{mV}$ from experiments as shown in Fig. 4 by fitting a double exponential function to the current traces, yielding the fast and the slow time constant of current activation at $+40 \mathrm{mV}$ as well as the amplitudes of the two current components $\left(A_{f}\right.$ and $\left.A_{s}\right)$. Please note, that the preceding holding potential was $-80 \mathrm{mV}$ except for the mutant $\mathrm{L} 352 \mathrm{~V}$ where a holding potential of $-100 \mathrm{mV}$ was used. Compared to wildtype $\mathrm{KCNH} 1$ channels, the time course of current activation was accelerated for all mutant channels. For G348R, I467V and L352V, both activation time constants were significantly decreased and for the double mutant S325Y/V356L, the slow time constant decreased significantly in combination with a higher relative contribution of the faster activating current component. (b) Families of wild-type and G348R current traces recorded with the depicted deactivation protocol. Zero current is indicated by a dashed line. (c) The time course of KCNH1 channel deactivation was analyzed at $-120 \mathrm{mV}$ from experiments as shown in $\boldsymbol{b}$. Compared to wild-type, the deactivation time course of all mutant channels was significantly slowed. Current decay upon hyperpolarization to $-120 \mathrm{mV}$ was fitted with a double exponential function, yielding the fast and the slow time constant of current deactivation as well as the amplitudes of the two current components $\left(A_{f}\right.$ and $\left.A_{s}\right)$. $A_{f}$ and $A_{s}$ were extrapolated to segment start, because the first 0.5 to 1 ms of the $-120 \mathrm{mV}$ pulse segment were not used for fitting to minimize contributions of capacitive currents. (a, c) The number of experiments is given in the lower bar plots; ${ }^{* *}$ : significantly different from wild-type with $p<0.001$. Values were tested for significant differences compared to wild-type data with a two-sided t-test and Bonferroni correction for multiple testing. 


\section{Supplementary Figure 5}

a

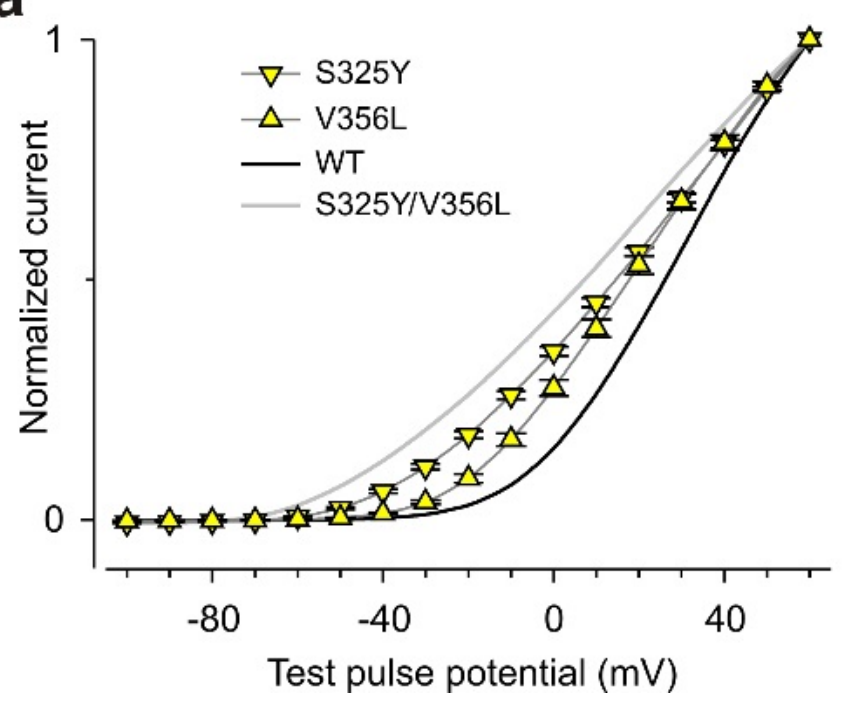

b

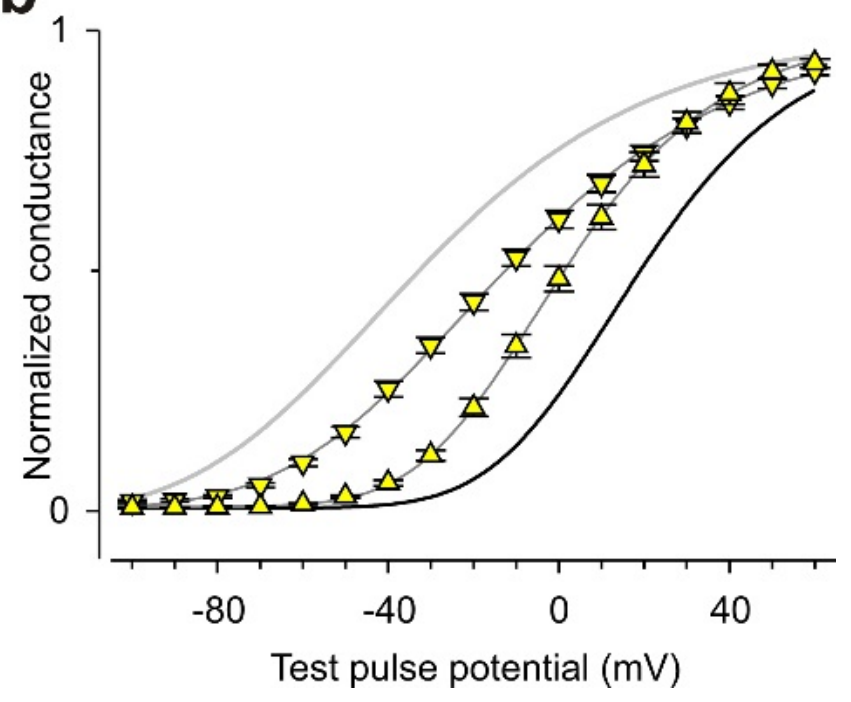

Supplementary Figure 5 Voltage dependence of S325Y and V356L KCNH1 channel activation.

Mean values ( \pm SEM) of normalized current amplitudes (a) and whole cell conductance (b) for S325Y $(n=14)$ and V356L $(n=11)$. Data points in (a) are connected by lines; the dark gray lines in (b) represent fits to the data points using Equation 2. Corresponding data for the double mutant S325Y/V356L and for wild-type (WT) channels are shown for comparison as light gray and black lines, respectively (data from Fig. 4). Fit parameters are given in Supplementary Table 5. 


\section{Supplementary Figure 6}

a

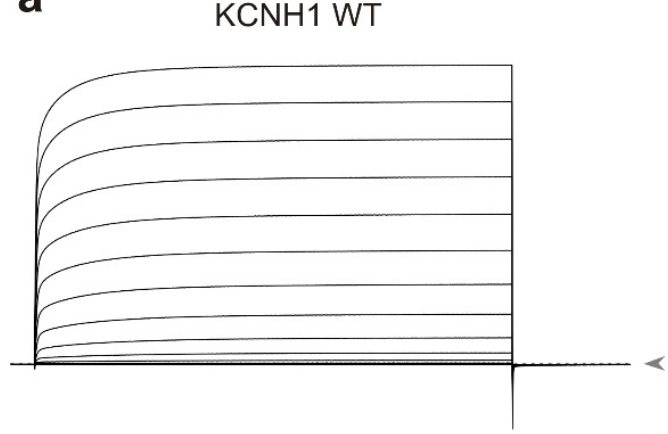

G469R

$$
\frac{\left.\right|^{4 \mu \mathrm{A}}}{0.2 \mathrm{~s}}
$$

0.2

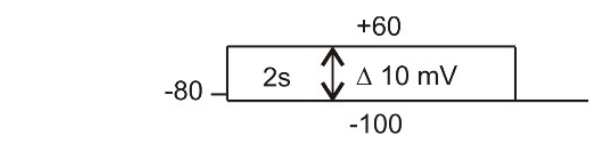

$\mathrm{KCNH} 1 \mathrm{WT}+\mathrm{G} 469 \mathrm{R}$

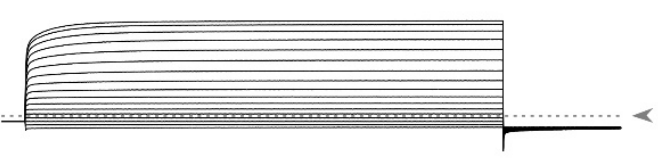

uninjected b Current (\% WT)

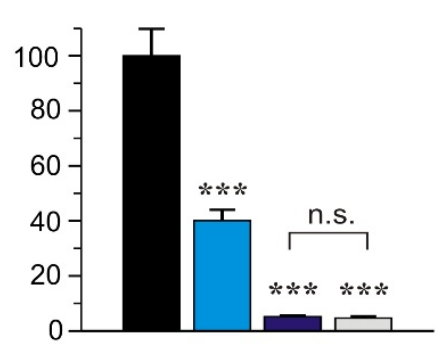

WT $5 \mathrm{ng}(21)$

WT $5 \mathrm{ng}+$ G469R 5ng (14)

G469R $5 \mathrm{ng}(16)$

uninjected (11)

Supplementary Figure 6 Expression and co-expression of wild-type (WT) and mutant (G469R) KCNH1 channels in oocytes of Xenopus laevis.

(a) Families of current traces recorded with the depicted pulse protocol. For the G469R mutant, depolarizing pulses failed to induce voltage-dependent outward currents and co-expression of the mutant with wild-type channels suppressed the amplitude of $\mathrm{KCNH} 1$ outward currents at more positive potentials. Zero current is indicated by dashed lines and arrowheads. (b) Means (+ SEM) of the current amplitude recorded at the end of the test pulse to $+40 \mathrm{mV}$. Absolute current values were normalized to the average current amplitude obtained for wild-type KCNH1 channels. ***: significantly different from WT with $\mathrm{p}<0.001$ (one way ANOVA and post hoc Bonferroni $t$-test); n.s.: not significantly different. The amount of injected CRNA is indicated and the number of experiments is given in parentheses. Similar results were obtained in experiments using other batches of oocytes. 


\section{Supplementary Table 1}

\begin{tabular}{|c|c|c|c|c|c|}
\hline Subject & 1 & 4 & 5 & 7 & 8 \\
\hline Target region coverage $\mathrm{e}^{1}$ & $97.7 \%$ & $99.6 \%$ & $99.4 \%$ & $98.6 \%$ & $98.3 \%$ \\
\hline Average sequencing depth on target & $36 x$ & $83 x$ & $56 x$ & $52 x$ & $57 x$ \\
\hline Number of variants with predicted functional effect & 9,542 & 10,698 & 10,861 & 10,693 & 10,652 \\
\hline $\begin{array}{l}\text { Novel, clinically associated and unknown/low } \\
\text { frequency }{ }^{2} \text { variants }\end{array}$ & 227 & 347 & 348 & 268 & 310 \\
\hline Shared candidate genes ( $\mathrm{X}$-linked trait) ${ }^{3}$ & 0 & 0 & 0 & 0 & 0 \\
\hline Shared candidate genes (autosomal recessive trait) ${ }^{3}$ & 0 & 0 & 0 & 0 & 0 \\
\hline \multirow[t]{2}{*}{ Shared candidate genes (autosomal dominant trait) ${ }^{3}$} & 1 & 1 & 1 & 1 & 1 \\
\hline & KCNH1 & KCNH1 & KCNH1 & ATP6V1B2 & ATP6V1B2 \\
\hline Genes with putative de novo variants & $6^{4}$ & $3^{5}$ & -6 & $7^{7}$ & 1 \\
\hline Shared genes with putative de novo variants & KCNH1 & KCNH1 & - & ATP6V1B2 & ATP6V1B2 \\
\hline
\end{tabular}

Supplementary Table 1 Whole exome sequencing data output.

${ }^{1}$ Referred to Nimblegen SeqCap EZ Library v.3.0 (Roche) (subjects 5 and 8), TruSeq Exome Enrichment kit (Illumina) (subjects 1 and 7), and SureSelect AllExon v.4 (Agilent) (subject 4).

${ }^{2} \mathrm{MAF}<0.1 \%$.

${ }^{3}$ Filtering by requiring the presence of functionally relevant variants (i.e. missense, nonsense and splice site changes, and coding indels; excluding variants with MAF $>0.1 \%$ ) in at least two affected subjects.

${ }^{4}$ VPS13C, SDK1, IKZF2, CLK4, KCNH1, SLC38A2.

${ }^{5} \mathrm{KCNH1}, \mathrm{TP} 5313, \mathrm{EVPL}$.

${ }^{6}$ Whole exome sequencing was performed in subject 5 and not his parents. Subject 5 inherited a second change in $K C N H 1$ (c.125T>C, p.142T) from his healthy mother (Supplementary Fig. 1). KCNH1 transcript analysis from total RNA of subject's skin fibroblasts following haplotype determination revealed that the $\mathrm{C} .125 \mathrm{~T}>\mathrm{C}$ and the de novo $\mathrm{C} .1054 \mathrm{C}>\mathrm{G}$ variant were in cis.

${ }^{7}$ CFHR5, PMS2, TJP2, NAV3, DNAJC25-GNG10, ATP6V1B2, GP1BA. 


\section{Supplementary Table 2}

\begin{tabular}{|c|c|c|c|c|c|c|c|}
\hline Subject & Chr & $\begin{array}{l}\text { Genomic } \\
\text { position }\end{array}$ & $\begin{array}{l}\text { Effect of } \\
\text { mutation }\end{array}$ & Gene & Nucleotide change & $\begin{array}{l}\text { Amino acid } \\
\text { change }\end{array}$ & rs ID \\
\hline \multirow{6}{*}{1} & 1 & 210977491 & missense & $K C N H 1^{a}$ & c. $1399 A>G$ & p.1467V & \\
\hline & 2 & 214012531 & missense & IKZF2 & c. $40 A>G$ & p.N14D & \\
\hline & 5 & 178040794 & missense & $C L K 4$ & c. $593 \mathrm{G}>\mathrm{A}$ & p.R198H & \\
\hline & 7 & 4050750 & (intron) & $S D K 1$ & c. $2279+5 G>A$ & & \\
\hline & 12 & $\begin{array}{c}46757701- \\
46757704\end{array}$ & (intron) & SLC38A2 & c.953+3_953+6delGAGT & & rs142524279 \\
\hline & 15 & 62174027 & missense & VPS13C & c. $9496 \mathrm{G}>\mathrm{A}$ & p.V3166I & \\
\hline \multirow{3}{*}{4} & 1 & 210977485 & missense & $K C N H 1^{a}$ & c. $1405 \mathrm{G}>\mathrm{A}$ & p.G469R & \\
\hline & 2 & 24305773 & nonsense & TP53/3 & c. $388 \mathrm{C}>\mathrm{T}$ & p.Q130* & rs143715832 \\
\hline & 17 & 74010607 & missense & $E V P L$ & c. $2273 \mathrm{G}>\mathrm{C}$ & p.C758S & rs142251448 \\
\hline \multirow{8}{*}{7} & 1 & 196963258 & frameshift & CFHR5 & c.486dupA & p.E163Rfs*35 & \\
\hline & 7 & 6029522 & missense & PMS2 & c. $1053 \mathrm{G}>\mathrm{C}$ & p.L351F & \\
\hline & 8 & 20077831 & missense & ATP6V1B2 & c. $1454 G>C$ & p.R485P & \\
\hline & 9 & 71866026 & missense & $T J P 2$ & c. $3067 \mathrm{G}>\mathrm{T}$ & p.A1023S & rs201317427 \\
\hline & 9 & 71866027 & missense & TJP2 & c. $3068 \mathrm{C}>\mathrm{T}$ & p.A1023V & rs199767035 \\
\hline & 9 & 114393695 & missense & $\begin{array}{c}\text { DNAJC25- } \\
\text { GNG10 }\end{array}$ & c. $8 \mathrm{C}>\mathrm{T}$ & p.A3V & \\
\hline & 12 & 78400847 & missense & NAV3 & c. $1529 \mathrm{G}>\mathrm{A}$ & p.S510N & rs61754793 \\
\hline & 17 & 4836861 & missense & GP1BA & c. $962 C>A$ & p.T321N & \\
\hline 8 & 8 & 20077831 & missense & ATP6V1B2 & c. $1454 G>C$ & p.R485P & \\
\hline
\end{tabular}

Supplementary Table 2 Putative de novo variants in the four parent-child trios identified by whole exome sequencing.

${ }^{a} K C N H 1$ nucleotide and amino acid changes are reported according to the short transcript variant/isoform 2 (NM_002238.3; NP_002229.1). The genomic position is given according to the human reference genome hg19. Chr, chromosome. 


\section{Supplementary Table 3}

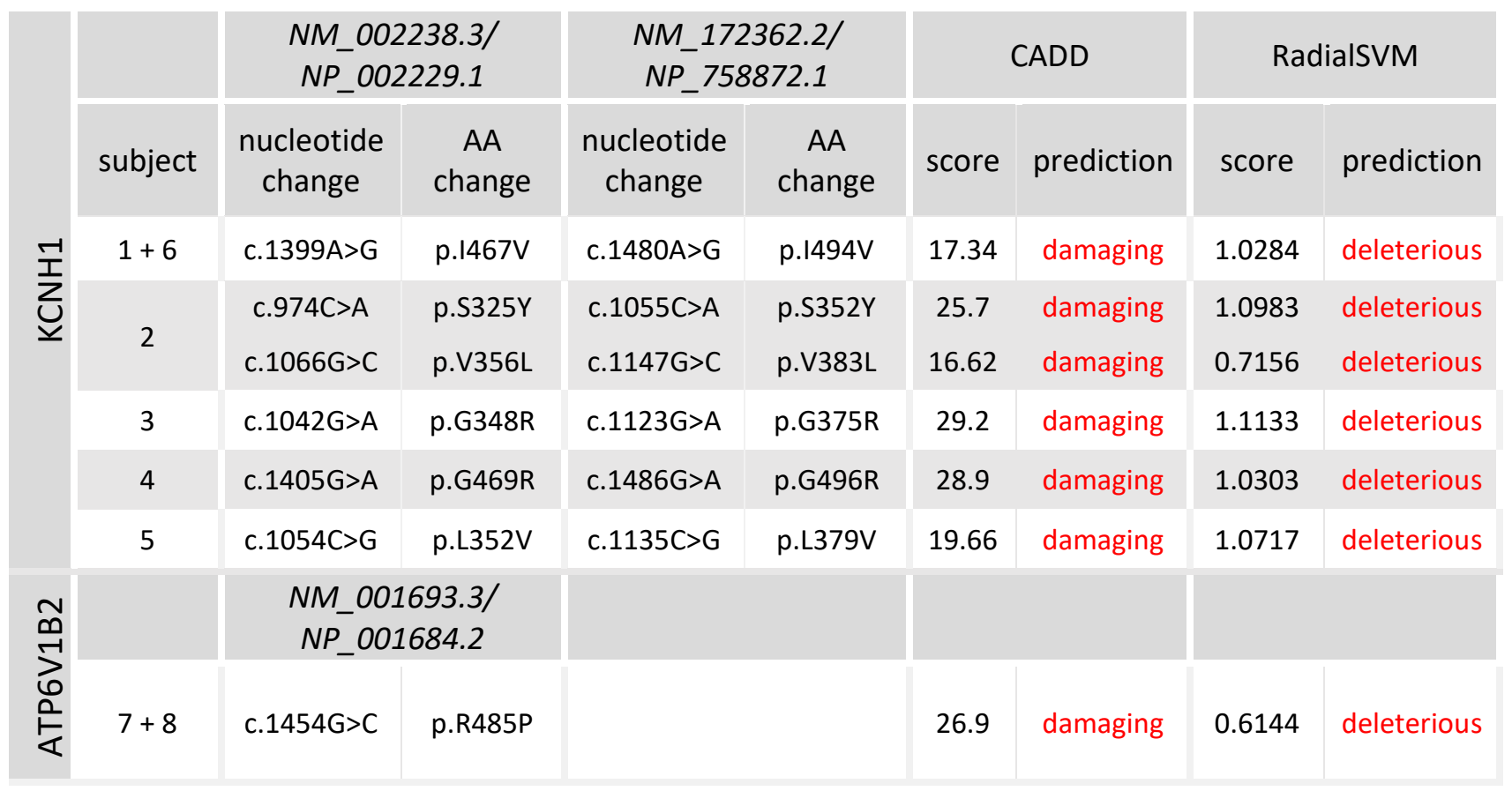

Supplementary Table 3 in silico pathogenicity prediction of amino acid substitutions in KCNH1 and ATP6V1B2. KCNH1 nucleotide and amino acid changes are described according to both the short transcript variant/isoform 2 (RNA RefSeq: NM_002238.3; Protein RefSeq: NP_002229.1) and long transcript variant/isoform 1 (RNA RefSeq: NM_172362.2; Protein RefSeq: NP_758872.1). The functional impact of the identified amino acid substitutions was predicted by Radial Support Vector Machine (RadialSVM) and Combined Annotation Dependent Depletion (CADD) scoring systems, using dbNSFP, an integrated database of functional annotations from multiple sources for the comprehensive collection of human non-synonymous SNPs ${ }^{1,2}$. RadialSVM score is an ensemble-based approach integrating multiple scoring systems (function prediction and conservation Score, i.e. SIFT, PolyPhen-2 HDIV, PolyPhen-2 HVAR, GERP++, MutationTaster, Mutation Assessor, FATHMM, LRT, SiPhy, PhyloP) and the maximum frequency observed in the 1000 genomes populations. RadialSVM prediction is based on the RadialSVM score, with a deleterious impact of the amino acid substitution predicted to having a value $>0$. CADD is a framework that integrates multiple annotations into one metric by contrasting variants that survived natural selection with simulated mutations. Reported CADD phred score is a phred-like rank score based on whole genome CADD raw scores. CADD raw scores were ranked among all CADD raw scores in dbNSFP. The larger the score the more likely the SNP has damaging effect. A cutoff on deleteriousness is generally set at 15 . 


\begin{tabular}{|c|c|c|c|c|c|c|}
\hline & $\mathbf{n}$ & $\mathrm{V}_{0.5}$ cond. $[\mathrm{mV}]$ & $V^{\prime}[\mathrm{mV}]$ & $s[\mathrm{mV}]$ & $\mathrm{V}_{0.5}$ activation $[\mathrm{mV}]$ & $k[\mathrm{mV}]$ \\
\hline WT-KCNH1 & 16 & $19.3 \pm 1.5$ & $-19.0 \pm 1.2$ & $23.1 \pm 0.4$ & $5.9 \pm 1.4$ & $13.2 \pm 0.2$ \\
\hline G348R & 16 & $-15.0 \pm 1.9 * * *$ & $-63.3 \pm 1.9 * * *$ & $29.2 \pm 0.8^{* * *}$ & $-37.6 \pm 1.9 * * *$ & $14.9 \pm 0.4^{*}$ \\
\hline I467V & 9 & $-24.2 \pm 1.8 * * *$ & $-81.6 \pm 3.6^{* * *}$ & $35.8 \pm 1.8^{* * *}$ & $-54.6 \pm 3.1 * * *$ & $16.8 \pm 0.6^{* * *}$ \\
\hline L352V & 9 & $-31.7 \pm 2.1 * * *$ & $-120.5 \pm 2.0 * * *$ & $53.2 \pm 2.1 * * *$ & $-88.4 \pm 1.5^{* * *}$ & $15.1 \pm 0.7^{*}$ \\
\hline S325Y/V356L & 13 & $-32.4 \pm 2.1 * * *$ & $-89.4 \pm 1.7 * * *$ & $34.1 \pm 1.1 * * *$ & $-61.6 \pm 1.6 * * *$ & $11.5 \pm 0.5^{*}$ \\
\hline S325Y & 14 & $-12.3 \pm 2.0 * * * \#$ & $-68.9 \pm 1.5 * * * \#$ & $34.1 \pm 0.9 * * *$ & $-41.1 \pm 1.5 * * * \#$ & $15.0 \pm 0.4^{* \#}$ \\
\hline V356L & 11 & $1.6 \pm 2.1 * * * \#$ & $-36.2 \pm 1.8 * * * \#$ & $22.9 \pm 1.0^{\text {n.s., \# }}$ & $-12.7 \pm 1.9 * * * \#$ & $12.6 \pm 0.4^{\text {n.s. }}$ \\
\hline G348R + WT & 6 & $4.1 \pm 2.2^{* * * x}$ & $-49.0 \pm 2.6 * * * z$ & $27.7 \pm 1.4^{* *}$ & $-23.0 \pm 2.4 * * * z$ & $14.5 \pm 0.4^{\text {n.s. }}$ \\
\hline
\end{tabular}

\begin{tabular}{|c|c|c|c|c|c|c|}
\hline G469R + WT & $\begin{array}{l}\text { rel. Ampl. } \\
\text { [\%]; } n=14\end{array}$ & $\begin{array}{c}\mathbf{V}^{\prime} \text { or } \mathrm{V}_{0.5} \text { cond. } \\
{[\mathrm{mV}]}\end{array}$ & $s$ or $k[\mathrm{mV}]$ & $\begin{array}{l}\text { rel. Ampl. } \\
{[\%] ; n=8}\end{array}$ & $\begin{array}{c}\mathrm{V}_{0.5} \text { activation } \\
{[\mathrm{mV}]}\end{array}$ & $k[\mathrm{mV}]$ \\
\hline component $a$ & $77.6 \pm 3.1$ & $-17.2 \pm 1.5^{\text {n.s. }}$ & $24.7 \pm 0.9^{\text {n.s. }}$ & $57.7 \pm 6.6$ & $7.3 \pm 1.4^{\text {n.s. }}$ & $13.2 \pm 0.5^{\text {n.s. }}$ \\
\hline component $b$ & $13.3 \pm 2.1$ & $-46.4 \pm 2.5$ & $13.0 \pm 1.1$ & $13.7 \pm 2.8$ & $-58.0 \pm 2.4$ & $10.9 \pm 1.7$ \\
\hline component $c$ & $9.2 \pm 1.6$ & $\mathrm{n} / \mathrm{a}$ & $\mathrm{n} / \mathrm{a}$ & $28.6 \pm 6.6$ & $n / a$ & $n / a$ \\
\hline
\end{tabular}

Supplementary Table 4 KCNH1 whole cell conductance and channel activation parameters.

Data are mean values \pm SEM resulting from fits to whole cell conductance data (left part of the table, light gray) and channel activation data (right part of the table, dark gray) derived from the Goldman-Hodgkin-Katz current equation (Equation 4; see Online Methods). Normalized whole cell conductance values were fitted with Equation 2, except the data obtained after co-expression of G469R with WT-KCNH1, which were fitted with Equation 3 (fit results in the lower part of the table). Please note that $V^{\prime}$ values obtained with equation 3 for component $\boldsymbol{a}$ correspond to $\mathrm{V}^{\prime}$ values obtained with equation 2. $V_{0.5}$ values obtained with equation 3 for component $\boldsymbol{b}$ correspond to $V_{0.5}$ conductance values. Channel activation data were fitted with a single first-order Boltzmann equation or with the sum of two first-order Boltzmann equations (Equation 5, for G469R + WT). n: number of experiments; n/a: not applicable; n.s.: not significantly different from the respective WT data; ${ }^{*},{ }^{* *},{ }^{* * *}$ : significantly different from WT with $p<0.05, p<0.01$, and $p<0.001$, respectively; \#: significantly different from the double mutant S325Y/V356L with $p<0.001 ;{ }^{x}$ : significantly different from G348R with $p<0.01 ;{ }^{z}$ : significantly different from G348R with $p<0.001$. Values for component $\boldsymbol{a}$ from G469R + WT co-expression were tested for significant differences compared to WT data with student's two-tailed unpaired $t$ test. All other statistical analyses were performed with one way ANOVA and post hoc Bonferroni $t$-test. 


\section{Supplementary Table 5}

\begin{tabular}{|c|c|c|c|c|c|c|c|c|}
\hline Subject \# & 1 & $2^{a}$ & $3^{a}$ & 4 & $5^{b}$ & 6 & $7^{a}$ & $8^{b}$ \\
\hline Gene & KCNH1 & KCNH1 & KCNH1 & KCNH1 & KCNH1 & KCNH1 & ATP6V1B2 & ATP6V1B2 \\
\hline Mutation $^{c}$ & $\begin{array}{l}\text { c. } 1399 A>G, p .1467 V \\
\text { c. } 1480 A>G, p .1494 V\end{array}$ & $\begin{array}{l}\text { c. } 974 C>A, p . S 325 Y ; \\
\text { c. } 1066 G>C, p . V 356 L \\
\text { c. } 1055 C>A, p . S 352 Y ; \\
\text { c. } 1147 G>C, p . V 383 L\end{array}$ & $\begin{array}{l}\text { c. } 1042 G>A, p . G 348 R \\
\text { c. } 1123 G>A, p . G 375 R\end{array}$ & $\begin{array}{l}\text { c. } 1405 G>A, p . G 469 R \\
\text { c. } 1486 G>A, p . G 496 R\end{array}$ & $\begin{array}{l}\text { c. } 1054 C>G, p . L 352 V \\
\text { c. } 1135 C>G, p . L 379 V\end{array}$ & $\begin{array}{l}\text { c. } 1399 \mathrm{~A}>\mathrm{G}, \mathrm{p} .1467 \mathrm{~V} \\
\text { c. } 1480 \mathrm{~A}>\mathrm{G}, \mathrm{p} .1494 \mathrm{~V}\end{array}$ & $\begin{array}{l}\text { c. } 1454 G>C, \\
\text { p.R485P }\end{array}$ & $\begin{array}{l}\text { c. } 1454 G>C, \\
\text { p.R485P }\end{array}$ \\
\hline Exon & 8 & 7 & 7 & 8 & 7 & 8 & 14 & 14 \\
\hline Origin & de novo & Both de novo & de novo & de novo, germline & de novo, germline & de novo & de novo & de novo \\
\hline Nationality & German & $\begin{array}{l}\text { Australian (English } \\
\text { and German } \\
\text { ancestry) }\end{array}$ & Australian & Italian & Italian & India & French & Italian \\
\hline Sex & $\mathrm{F}$ & $M$ & $\mathrm{~F}$ & $\mathrm{~F}$ & $M$ & $\mathrm{~F}$ & $M$ & $\mathrm{~F}$ \\
\hline $\operatorname{Age}^{d}$ & 12 y $8 \mathrm{~m}$ & $21 y$ & $19 y$ & $12 \mathrm{y}$ & $7 y$ & 4 y $6 \mathrm{~m}$ & 22 y $7 \mathrm{~m}$ & 5 y $6 \mathrm{~m}$ \\
\hline $\begin{array}{l}\text { Birth weight } \\
\text { (centile) }\end{array}$ & $\begin{array}{c}4000 \mathrm{~g}(40 \mathrm{wks}) \\
\left(86^{\text {th }}\right)\end{array}$ & $\begin{array}{c}3700 \mathrm{~g} \text { (39 wks) } \\
\left(77^{\text {th }}\right)\end{array}$ & $\begin{array}{c}3290 \mathrm{~g} \text { (39 wks) } \\
\left(54^{\text {th }}\right)\end{array}$ & $\begin{array}{c}3070 \mathrm{~g} \text { (38 wks) } \\
\left(52^{\text {th }}\right)\end{array}$ & $\begin{array}{c}2430 \mathrm{~g}(37 \mathrm{wks}) \\
\left(12^{\text {th }}\right)\end{array}$ & na & $\begin{array}{c}3540 \mathrm{~g} \text { (38 wks) } \\
\left(80^{\text {th }}\right)\end{array}$ & $\begin{array}{c}2800 \mathrm{~g} \text { (39 wks) } \\
\left(17^{\text {th }}\right)\end{array}$ \\
\hline $\begin{array}{l}\text { Birth length } \\
\text { (centile) }\end{array}$ & $55 \mathrm{~cm}\left(98^{\text {th }}\right)$ & $48 \mathrm{~cm}\left(16^{\text {th }}\right)$ & $55 \mathrm{~cm}\left(99^{\text {th }}\right)$ & $51 \mathrm{~cm}\left(84^{\text {th }}\right)$ & $47 \mathrm{~cm}\left(30^{\text {th }}\right)$ & na & $49 \mathrm{~cm}\left(45^{\text {th }}\right)$ & $48 \mathrm{~cm}\left(25^{\mathrm{th}}\right)$ \\
\hline OFC birth (centile) & $37.5 \mathrm{~cm}\left(98^{\text {th }}\right)$ & $36 \mathrm{~cm}\left(85^{\text {th }}\right)$ & nd & nd & $33 \mathrm{~cm}\left(4^{\text {th }}\right)$ & na & $35 \mathrm{~cm}\left(76^{\text {th }}\right)$ & $31 \mathrm{~cm}\left(1^{\mathrm{st}}\right)$ \\
\hline OFC $^{c}$ (centile) & $56.8 \mathrm{~cm}\left(99^{\text {th }}\right)$ & $56 \mathrm{~cm}\left(50^{\text {th }}\right)$ & $48.5 \mathrm{~cm}\left(<3^{r d}\right)$ & $56 \mathrm{~cm}\left(97^{\text {th }}\right)$ & $51 \mathrm{~cm}\left(12^{\text {th }}\right)$ & $\left(<3^{\text {rd }}\right)$ & $55 \mathrm{~cm}$ & $51 \mathrm{~cm}\left(56^{\text {th }}\right)$ \\
\hline Height $^{c}$ (centile) & $155 \mathrm{~cm}\left(47^{\text {th }}\right)$ & $165 \mathrm{~cm}$ & $150 \mathrm{~cm}$ & $155 \mathrm{~cm}\left(71^{\text {th }}\right)$ & $121 \mathrm{~cm}\left(47^{\mathrm{th}}\right)$ & $\left(<3^{r d}\right)$ & $157.5 \mathrm{~cm}$ & $115 \mathrm{~cm}\left(78^{\text {th }}\right)$ \\
\hline Weight $^{c}$ (centile) & $40 \mathrm{~kg}\left(29^{\mathrm{th}}\right)$ & $48 \mathrm{~kg}\left(<3^{\text {rd }}\right)$ & nd & $62.5 \mathrm{~kg}\left(96^{\text {th }}\right)$ & $21 \mathrm{~kg}\left(21^{\text {th }}\right)$ & $\left(<3^{\text {rd }}\right)$ & $62 \mathrm{~kg}$ & $30 \mathrm{~kg}\left(99^{\mathrm{th}}\right)$ \\
\hline $\mathrm{DD} / \mathrm{ID}$ & $\begin{array}{l}\text { Severe, } \\
\text { autism }\end{array}$ & Profound & Severe/profound & $\begin{array}{l}\text { IQ: 55; verbal: } 80 \text {, } \\
\text { performance: } 41\end{array}$ & $\begin{array}{l}\text { Severe intellectual } \\
\text { and motor disability }\end{array}$ & Severe & Global/severe & Global/mild \\
\hline Tonus & Hypotonia & Hypotonia & Hypotonia & Normal & $\begin{array}{l}\text { Limb and facial } \\
\text { hypotonia }\end{array}$ & Normal & Hypotonia & $\begin{array}{l}\text { Generalized } \\
\text { hypotonia }\end{array}$ \\
\hline
\end{tabular}


Supplementary Information Kortüm et al. 14

\begin{tabular}{|c|c|c|c|c|c|c|c|c|}
\hline Seizures & $\begin{array}{l}\text { Generalized tonic } \\
\text { clonic seizures } \\
\text { starting at the age } \\
\text { of } 10 \text { y } 6 \mathrm{~m} \text {, therapy } \\
\text { with valproic acid } \\
\text { since } 12 \text { y } 6 \mathrm{~m}\end{array}$ & $\begin{array}{l}\text { Frequent seizures } \\
\text { from childhood }\end{array}$ & $\begin{array}{l}\text { Infrequent, started } \\
\text { in adolescence }\end{array}$ & $\begin{array}{c}\text { Focal epilepsy onset } \\
\text { at } 6 \mathrm{~m} \text { (controlled } \\
\text { with Tegretol } 350 \\
\mathrm{mg} / \mathrm{d} \text { ) }\end{array}$ & $\begin{array}{c}\text { At age } 8 \text { months: } \\
\text { generalized drug- } \\
\text { resistant seizures; } \\
\text { phenobarbital (8-17 } \\
\text { months); valproate } \\
\text { from age } 17 \text { months } \\
\text { to } 3 \text { years; after- } \\
\text { wards: lamotrigine, } \\
\text { levetiracetam, ino- } \\
\text { velon, topiramate, } \\
\text { clonazepam }\end{array}$ & $\begin{array}{l}\text { Neonatal treated } \\
\text { with phenobarbital, } \\
\text { then one right focal } \\
\text { motor seizure at } 4 \\
y, \text { controlled with } \\
\text { phenytoin, then } \\
\text { valproic acid was } \\
\text { added; currently, } \\
\text { on valproic acid at } \\
30 \mathrm{mg} / \mathrm{kg} / \mathrm{day}\end{array}$ & - & - \\
\hline EEG & $\begin{array}{c}\text { Multifocal, } \\
\text { predominantly } \\
\text { frontal, sharp slow } \\
\text { waves, slowing of } \\
\text { background activity }\end{array}$ & $\begin{array}{l}\text { Frequent right } \\
\text { occipital spikes on a } \\
\text { generally slow } \\
\text { background }\end{array}$ & nd & $\begin{array}{l}\text { Frontotemporal } \\
\text { abnormal slow } \\
\text { electric activity, } \\
\text { bilaterally }\end{array}$ & $\begin{array}{c}\text { subcontinuous } \\
\text { multifocal epileptic } \\
\text { activity (at } 7 \text { years) }\end{array}$ & $\begin{array}{l}\text { Generalized } \\
\text { epileptiform } \\
\text { activity }\end{array}$ & Encephalopathy & Normal \\
\hline MRI scan & $\begin{array}{l}4 \text { y } 9 \mathrm{~m} \text { : asymmetric } \\
\text { ventricles, right } \\
\text { ventricle larger than } \\
\text { left, no brain } \\
\text { malformation }\end{array}$ & na & na & Normal & $\begin{array}{c}\text { Mild dilatation of } \\
\text { the cavum vergae } \\
\text { and expansion of } \\
\text { subarachnoid spaces } \\
\text { at temporal lobes }\end{array}$ & Normal & Normal & na \\
\hline Hearing & Normal & Normal & Normal & na & na & $\begin{array}{l}\text { Severe SNHL on } \\
\text { right, moderate } \\
\text { SNHL on left }\end{array}$ & $\begin{array}{l}\text { Unilateral total } \\
\text { deafness }\end{array}$ & Normal \\
\hline Eye findings & Normal & Normal & Normal & $\begin{array}{c}\text { Myopia, oculomotor } \\
\text { apraxia }\end{array}$ & Normal & $\begin{array}{l}\text { Horizontal } \\
\text { nystagmus } \\
\text { bilaterally }\end{array}$ & Normal & $\begin{array}{c}\text { Palpebral fissure } \\
\text { length } 2.6 \mathrm{~cm}(>+1 \\
\text { SD), inner canthal } \\
\text { distance } 3.2 \mathrm{~cm}(>+1 \\
\text { SD), outer canthal } \\
\text { distance } 8.4 \mathrm{~cm} \text { (50- } \\
75 \text { th centile) }\end{array}$ \\
\hline $\begin{array}{l}\text { Craniofacial } \\
\text { dysmorphism }\end{array}$ & $\begin{array}{l}\text { Thick, fuzzy scalp } \\
\text { hair, } \\
\text { dolichocephaly, } \\
\text { macrocephaly, long } \\
\text { and coarse face }\end{array}$ & $\begin{array}{l}\text { Thick scalp hair, } \\
\text { thick eyebrows, } \\
\text { broad forehead, } \\
\text { coarse facies, broad } \\
\text { nasal tip, short } \\
\text { philtrum, thick lips, }\end{array}$ & $\begin{array}{c}\text { Macroglossia } \\
\text { secondary to gum } \\
\text { overgrowth, central } \\
\text { incisor, arched } \\
\text { eyebrows }\end{array}$ & $\begin{array}{l}\text { Thick eyebrows, } \\
\text { large nose, bulbous } \\
\text { nasal tip, thick helix, } \\
\text { macrostomia, thick } \\
\text { upper and lower lip, }\end{array}$ & $\begin{array}{l}\text { Mild turricephaly, } \\
\text { arched eyebrows, } \\
\text { bilateral eyelid } \\
\text { ptosis, long } \\
\text { eyelashes, long }\end{array}$ & $\begin{array}{l}\text { Low set ears with } \\
\text { mild dysplasia of } \\
\text { the right one, high } \\
\text { forehead, pointed } \\
\text { nose, prominent } \\
\text { alae nasi, mild }\end{array}$ & $\begin{array}{l}\text { Coarse face, thick } \\
\text { scalp hair, } \\
\text { synophrys, large } \\
\text { bulbous nose with } \\
\text { "bifid" nasal tip, }\end{array}$ & $\begin{array}{l}\text { Widow's peak, thick } \\
\text { and laterally flared } \\
\text { eyebrows, long } \\
\text { eyelashes, mildly } \\
\text { upslanting palpebral } \\
\text { fissures, prominent }\end{array}$ \\
\hline
\end{tabular}


Supplementary Information Kortüm et al. 15

\begin{tabular}{|c|c|c|c|c|c|c|c|c|}
\hline & & \begin{tabular}{|} 
broadly spaced \\
teeth, thickened \\
alveolar ridges, large \\
ears with anteverted \\
and thickened ear \\
helices, full cheeks
\end{tabular} & & $\begin{array}{l}\text { malocclusion, low } \\
\text { frontal hairline }\end{array}$ & $\begin{array}{l}\text { philtrum, macro- } \\
\text { glossia with } \\
\text { protruding tongue, } \\
\text { nose very } \\
\text { soft at palpation }\end{array}$ & $\begin{array}{l}\text { hypertelorism, } \\
\text { epicanthal folds, } \\
\text { long philtrum, large } \\
\text { lower lips, down } \\
\text { turned angle of } \\
\text { mouth }\end{array}$ & $\begin{array}{l}\text { thick lips, } \\
\text { macroglossia }\end{array}$ & $\begin{array}{l}\text { nasal septum with } \\
\text { hypoplastic alae nasi } \\
\text { and "bifid" nasal tip, } \\
\text { prominent philtrum, } \\
\text { thick helices and ear } \\
\text { lobules, nose and } \\
\text { ear cartilages } \\
\text { extremely soft, } \\
\text { short neck }\end{array}$ \\
\hline $\begin{array}{l}\text { Gingival } \\
\text { enlargement }\end{array}$ & $\begin{array}{l}\text { Marked and present } \\
\text { from the first } \\
\text { dentation }(\sim 1 \mathrm{y})\end{array}$ & $\begin{array}{l}\text { Present from } \\
\text { infancy (prior to } \\
\text { anticonvulsant } \\
\text { treatment) }\end{array}$ & $\begin{array}{l}\text { Marked (noticed in } \\
\text { childhood prior } \\
\text { anticonvulsant } \\
\text { treatment), two } \\
\text { reduction } \\
\text { procedures }\end{array}$ & $\begin{array}{c}+ \\
\text { (prior to } \\
\text { anticonvulsant } \\
\text { treatment) }\end{array}$ & $\begin{array}{l}\text { With unerupted } \\
\text { upper incisors }\end{array}$ & - & Marked & $\begin{array}{l}\text { Of upper and lower } \\
\text { alveoli with } \\
\text { normally erupted } \\
\text { decidual teeth }\end{array}$ \\
\hline $\begin{array}{l}\text { Skeletal } \\
\text { abnormalities of } \\
\text { hands and feet }\end{array}$ & $\begin{array}{l}\text { Small hands and } \\
\text { feet; hypoplastic } \\
\text { terminal phalanges: } \\
\text { left thumb, great } \\
\text { toe and } 3^{\text {rd }} \text { to } 5^{\text {th }} \\
\text { toes of the left foot; } \\
\text { aplastic terminal } \\
\text { phalanx of the left } \\
2^{\text {nd }} \text { toe }\end{array}$ & na & $\begin{array}{c}\text { Hypoplastic terminal } \\
\text { phalanges of hands } \\
\text { and feet }\end{array}$ & Asymmetric limbs & $\begin{array}{l}\text { Hypoplasia of the } 1^{\text {st }} \\
\text { distal phalanx of } \\
\text { both hands and feet }\end{array}$ & $\begin{array}{l}\text { Mild hypoplasia of } \\
\text { the terminal } \\
\text { phalanges of both } \\
\text { fingers and toes }\end{array}$ & $\begin{array}{l}\text { Aplastic terminal } \\
\text { phalanges: } 2^{\text {nd }} \text { and } \\
5^{\text {th }} \text { left and } 5^{\text {th }} \text { right } \\
\text { digits and of all toes } \\
\text { except } 1^{\text {st }} ; \text { valgus } \\
\text { deformity of feet }\end{array}$ & $\begin{array}{l}\text { Hands: } 2^{\text {nd }}-4^{\text {th }} \\
\text { fingers markedly } \\
\text { shortened with } \\
\text { tapering ends, } \\
\text { relative sparing of } \\
\text { the right }{ }^{\text {rd }} \text { finger, } \\
\text { thumbs elongated, } \\
\text { fingerpads present } \\
\text { and more marked } \\
\text { on } 1^{\text {st }} 2^{\text {nd }} \text { and } 5^{\text {th }} \\
\text { fingers; } \\
\text { feet: toes equally } \\
\text { shortened with pads } \\
\text { emerging from the } \\
\text { dorsal aspect of } \\
\text { their tips }\end{array}$ \\
\hline $\begin{array}{l}\text { Aplastic/ } \\
\text { hypoplastic nails }\end{array}$ & $\begin{array}{l}\text { Aplastic nails - } \\
\text { hands: right thumb; } \\
\text { feet: both great } \\
\text { toes; hypoplastic } \\
\text { nails of all other } \\
\text { fingers and toes }\end{array}$ & $\begin{array}{c}\text { Aplastic nails - } \\
\text { hands: both thumbs } \\
\text { and left } 5^{\text {th }} \text { finger; } \\
\text { feet: } 1^{\text {st }} \text { to } 3^{\text {rd }} \text { toes; } \\
\text { hypoplastic nails of } \\
\text { all other fingers and } \\
\text { toes }\end{array}$ & $\begin{array}{l}\text { Aplastic nails - } \\
\text { hands: all; } \\
\text { feet: all }\end{array}$ & - & $\begin{array}{l}\text { Anonychia of } \\
\text { thumbs and great } \\
\text { toes; hypoplasia of } \\
\text { nails - hands: left } 4^{\text {th }} \\
\text { and } 5^{\text {th }} \text { finger; feet: } \\
\text { remaining toenails } \\
\text { rudimentary }\end{array}$ & $\begin{array}{l}\text { Hyponychia of all } \\
\text { fingers and all toes, } \\
\text { anonychia of great } \\
\text { toe bilaterally }\end{array}$ & $\begin{array}{c}\text { Anonychia of hand } \\
\text { and feet }\end{array}$ & $\begin{array}{c}\text { Anonychia of hand } \\
\text { and feet }\end{array}$ \\
\hline
\end{tabular}


Supplementary Information Kortüm et al. 16

\begin{tabular}{|c|c|c|c|c|c|c|c|c|}
\hline Scoliosis & Thoracic & Severe & Thoracic & + & Thoracic kyphosis & - & $\begin{array}{c}\text { Severe } \\
\text { kyphosis/lordosis }\end{array}$ & nd \\
\hline Hypertrichosis & $\begin{array}{l}\text { Moderate, since the } \\
\text { age of } \sim 8 y\end{array}$ & - & - & $\begin{array}{c}\text { Moderate } \\
\text { (especially on limbs) }\end{array}$ & Cervical hirsutism & - & Marked & $\begin{array}{l}\text { Hirsutism on back } \\
\text { and limbs }\end{array}$ \\
\hline Other anomalies & $\begin{array}{l}\text { Gastrooesophageal } \\
\text { reflux, hip dysplasia } \\
\text { and flat and skew } \\
\text { feet (surgery at age } \\
5 \text { y bilaterally), } \\
\text { constipation }\end{array}$ & $\begin{array}{c}\text { Gastrooesophageal } \\
\text { reflux, episodes of } \\
\text { apnoea, consti- } \\
\text { pation, excessive } \\
\text { drooling }\end{array}$ & $\begin{array}{l}\text { Short stature, } \\
\text { solitary renal cyst }\end{array}$ & $\begin{array}{l}\text { Ataxia, intentional } \\
\text { tremor, motor } \\
\text { clumsiness, } 2 \text { cafè- } \\
\text { au-lait spots }\end{array}$ & $\begin{array}{l}\text { Trunk ataxia, ske- } \\
\text { letal muscle hypo- } \\
\text { trophy, consti- } \\
\text { pation, pectus } \\
\text { carinatum }\end{array}$ & - & $\begin{array}{l}\text { Short stature, } \\
\text { macroorchidism }\end{array}$ & $\begin{array}{l}\text { Dermatoglyphs } \\
\text { were A-W-A-W-W } \\
\text { on the left and W- } \\
\text { W-A-W-W on the } \\
\text { right, generalized } \\
\text { joint hypermobility }\end{array}$ \\
\hline Subject \# & 1 & 2 & 3 & 4 & 5 & 6 & 7 & 8 \\
\hline
\end{tabular}

Supplementary table 5 Clinical data from individuals with Zimmermann-Laband syndrome and a mutation in KCNH1 or ATP6V1B2.

a, published in Abo-Dalo et al. 2008 (ref. 3; subject 2 is patient 9 (Table 2), subject 3 is patient 7 (Table 1) and subject 7 is patient 6 (Table 1)); ', published in Castori et al. 2013 (ref. 4; subject 8 is patient 1 and subject 5 is patient 2); ', KCNH1 mutations are reported according to the short transcript variant/isoform 2 (RNA RefSeq: NM_002238.3; Protein RefSeq: NP_002229.1; upper description) and the long transcript variant/isoform 1 (RNA RefSeq: NM_172362.2; Protein RefSeq: NP_758872.1; lower description); ${ }^{2}$, at last follow up.

Abbreviations: +, present; -, absent; A, arch; DD/ID, developmental delay/intellectual disability; EEG, electroencephalogram; F, female; M, male; m, month(s); MRI, magnetic resonance imaging; na, not analysed; nd, not documented; OFC, occipital frontal circumference; w, whorl; wks, weeks of gestation; y, year(s).

\section{REFERENCES:}

1. Kircher, M. et al. A general framework for estimating the relative pathogenicity of human genetic variants. Nat. Genet. 46, 310-315 (2014).

2. Liu, X., Jian, X. \& Boerwinkle, E. dbNSFP v2.0: a database of human non-synonymous SNVs and their functional predictions and annotations. Hum. Mutat. 34, E2393E2402 (2013).

3. Abo-Dalo, B. et al. No mutation in genes of the WNT signaling pathway in patients with Zimmermann-Laband syndrome. Clin. Dysmorphol. 17, 181-185 (2008).

4. Castori, M. et al. Clinical and genetic study of two patients with Zimmermann-Laband syndrome and literature review. Eur. J. Med. Genet. 56, 570-576 (2013). 